\title{
Surrounding Rock Movement of Steeply Dipping Coal Seam Using Backfill Mining
}

\author{
Wenyu Lv $\left(\mathbb{D},{ }^{1,2}\right.$ Kai Guo $\mathbb{D}^{1},{ }^{1}$ Jianhao Yu $\mathbb{D}^{3},{ }^{3}$ Xufeng Du $\left(\mathbb{D},{ }^{1}\right.$ and Kun Feng ${ }^{4}$ \\ ${ }^{1}$ School of Energy Engineering, Xi'an University of Science and Technology, Xi'an 710054, China \\ ${ }^{2}$ Henan Key Laboratory for Green and Efficient Mining \& Comprehensive Utilization of Mineral Resources, \\ Henan Polytechnic University, Jiaozuo 454000, China \\ ${ }^{3}$ Institute of Mining Technology, China Coal Mining Research Institute Co., Ltd., Beijing 100013, China \\ ${ }^{4}$ Shandong Mining Machinery Huaneng Equipment Manufacturing Co., Ltd., Weifang 261000, China
}

Correspondence should be addressed to Wenyu Lv; lvwenyu@xust.edu.cn

Received 19 February 2021; Accepted 24 April 2021; Published 12 May 2021

Academic Editor: Bo Tan

Copyright (c) 2021 Wenyu Lv et al. This is an open access article distributed under the Creative Commons Attribution License, which permits unrestricted use, distribution, and reproduction in any medium, provided the original work is properly cited.

\begin{abstract}
The movement of the overlying strata in steeply dipping coal seams is complex, and the deformation of roof rock beam is obvious. In general, the backfill mining method can improve the stability of the surrounding rock effectively. In this study, the 645 working face of the tested mine is used as a prototype to establish the mechanical model of the inclined roof beam using the sloping flexible shield support backfilling method in a steeply dipping coal seam, and the deflection equation is derived to obtain the roof damage structure and the maximum deflection position of the roof beam. Finally, numerical simulation and physical similarity simulation experiments are carried out to study the stability of the surrounding rock structure under backfilling mining in steeply dipping coal seams. The results show the following: (1) With the support of the gangue filling body, the inclined roof beam has smaller roof subsidence, and the maximum deflection position moves to the upper part of working face. (2) With the increase of the stope height, the stress and displacement field of the surrounding rock using the backfilling method show an asymmetrical distribution, the movement, deformation, and failure increase slowly, and the increase of the strain is relatively stable. Compared with the caving method, the range and degree of the surrounding rock disturbed by the mining stress are lower. The results of numerical simulation and physical similarity simulation experiment are generally consistent with the theoretically derived results. Overall, this study can provide theoretical basis for the safe and efficient production of steeply dipping coal seams.
\end{abstract}

\section{Introduction}

Steeply inclined coal seams (SDCS) are the coal seam with an inclination angle greater than 45 degrees, which are mainly distributed in western China, such as Xinjiang, Sichuan, and Chongqing, accounting for about $20 \%$ of the proven reserves and $10 \%$ of the total coal production in China [1]. Mining the SDCS has been widely known as a major challenge in mining operations. One of the essential tasks to maintain a safe and efficient mining process is to adopt an effective control over the stability of surrounding rock $[2,3]$. However, the main rock movement and deformation characteristics of the surrounding rock are significantly different from those of gently inclined or nearly horizontal coal seams, especially for the deformation and fracture laws of overlying strata $[4,5]$. In the mining process of SDCS, with the increase of dip angle, the tangential component of gravity increases, the normal component decreases, and the collapsed roof slides to the lower part forming a nonuniform filling effect. Along the inclined direction of the working face, the roof movement, deformation and failure characteristics of the upper area are active, and the stability control of surrounding rock are more difficult, which can easily cause operational accidents $[1,6]$. Wu et al. defined the concept of SDCS for the first time and provided an engineering explanation and proposed the "R-S-F" system 
dynamics control theory, which lays the theoretical and technical foundation for SDCS mining [6, 7]. Tu et al. studied the filling and compaction characteristic of the gangue in SDCS mining faces, proposed the ear-shaped bearing shell of immediate roof, and revealed the structural model characteristic of the inclined masonry beam of main roof [8]. Based on the occurrence conditions of the SDCS in Longhu Mine of Longmei Group, Li and Zhai et al. established an inclined backfilling mining model, and they analyzed the stability of overlying strata and waterproof coal pillars, movement of floor rock beam, stress distribution characteristics, and the evolution law of water-flowing fractures [9, 10]. Dong studied the characteristic of the movement, deformation, and failure for overlying strata under the conditions of unfilled, full-filled, and strip-filled mining in the SDCS and conducted the economic and technical comparative analyses [11]. Yao et al. established the mechanical model of inclined roof beam of the segmented cemented backfilling face in SDCS and deduced the deflection equation as well as calculating the maximum deflection positions of filled and unfilled area [12].

In summary, although different theories were proposed to study the SDCS mining under different engineering backgrounds, current studies on the SDCS mining still have certain limitations and differences $[13,14]$. The deformation and fracture formation of the overlying strata in SDCS is nonuniform and asymmetric, and the failure mechanism is complicated $[15,16]$. Moreover, there are even fewer studies on the SDCS using the backfill mining method. Although many scholars have established different mechanical models on the roof beam using the backfilling method, the majority of these researches are based on the theories of elastic foundation beams and thin slabs as well as using fixed beams at both ends without considering the lateral force of roof beam [17-21]. Therefore, this paper proposes the sloping flexible shield support backfilling method in the SDCS, and the 645 working face of a test mine is taken as the engineering background. Based on theoretical analyses and numerical simulations, the mechanical model of the inclined roof beam is established, the lateral force is increased, and the movement, deformation, and failure law of roof beam is explored, which is of great significance to the mine pressure control of SDCS mining.

\section{Sloping Flexible Shield Support Backfilling Method in SDCS}

The backfill mining method can not only control the strata movement and surface subsidence, improve the "three under" coal resource recovery and solve the problem of gangue discharge, but can also effectively inhibit the dynamic phenomenon of the coal seam, roof and floor, slow down the mine pressure behavior, effectively inhibit the movement and deformation of surrounding rock, and improve its stability [9-12]. Aiming at resolving the poor safety and low efficiency traditional flexible shield support backfilling methods $[22,23]$, this paper designs a sloping flexible shield support backfilling method, where the roadway adopts the layout method of slope mining. In the lower part of the stage, the main roadway passes through the crosscut into the coal seam, while in the upper stage, the coal is mined from the main airway through the windstone gate. The mining area roadway is arranged in coal seam, while the slope roadway is arranged along the pseudoslope, whose angle is $25^{\circ}$ to $30^{\circ}$, and the working face advances continuously along the strike direction. The mining unit is called a warehouse, in which the length is about 50 to $70 \mathrm{~m}$. First, the mining system is formed by drifting the open cut. The slope of the working face is maintained at $25^{\circ}$ to $30^{\circ}$ and adjusted to $25^{\circ}$ to $27^{\circ}$ at the end, while the slope is no more than $18^{\circ}$ within $5 \mathrm{~m}$ from the upper warehouse. The roadway layout is shown in Figure 1. This mining method can overcome some shortcomings of flexible shield support mining method, which not only reduces the roadway excavation rate and coal pillar, increases the recovery rate, but also improves the ventilation environment of working face. A safety exit is set up at the upper and lower levels of mining area, which realizes the safe and reliable negative pressure ventilation as well as the safe and reliable ventilation system.

\section{Mechanical Model of the Inclined Roof Beam}

In this section, the inclined roof beam of sloping flexible shield support backfilling face in the SDCS is taken as the research object, and the variation characteristics of the deflection, rotation angle, and bending moment are analyzed. The roof mechanical model of the gangue backfilling mining is established by adopting the theoretical analysis method.

3.1. Model Design. According to the complexity of stress on the roof beam along the inclined direction of working face, the roof beam of the unit width is taken for stress analysis. The filling reaction $(P)$ changes gradually to 0 with the compaction degree from the bottom to top, and it follows a linear distribution. The expression is as follows:

$$
P(x)=q_{1}\left(1-\frac{x}{L}\right), \quad 0 \leq x \leq L,
$$

where $q_{1}$ is the maximum value of the filling reaction, $\mathrm{kN} / \mathrm{m}$.

The mechanical model can be simplified as shown in Figure 2. The load of filling reaction satisfies the triangular distribution characteristics and corresponds to the load $q$, i.e., $q_{1}=q$. As shown in Figure 2, $\alpha$ is the inclination angle, ${ }^{\circ}$; $E$ is the elastic modulus of roof beam, $\mathrm{MPa} ; I$ is the inertia moment of roof beam, $\mathrm{m}^{4} ; L$ is the working face length, $\mathrm{m}$; and $H$ is the width of the roof beam, m. Because the buried depth of coal seam is much larger than the vertical projection on the length of working face, it is assumed that an evenly distributed load is applied to the roof beam, i.e., $q=\gamma Y_{a} \cos \alpha$. The load for the upper area of the working face is $S=\gamma Y_{a} \sin \alpha H$, where $\gamma$ is the volumetric weight, $\mathrm{kN} /$ $\mathrm{m}^{3} ; Y_{a}$ is the depth of the coal seam, m. $A$ is the coordinate origin, $x$ is for the inclination direction of working face, and $y$ is for the perpendicular direction. 


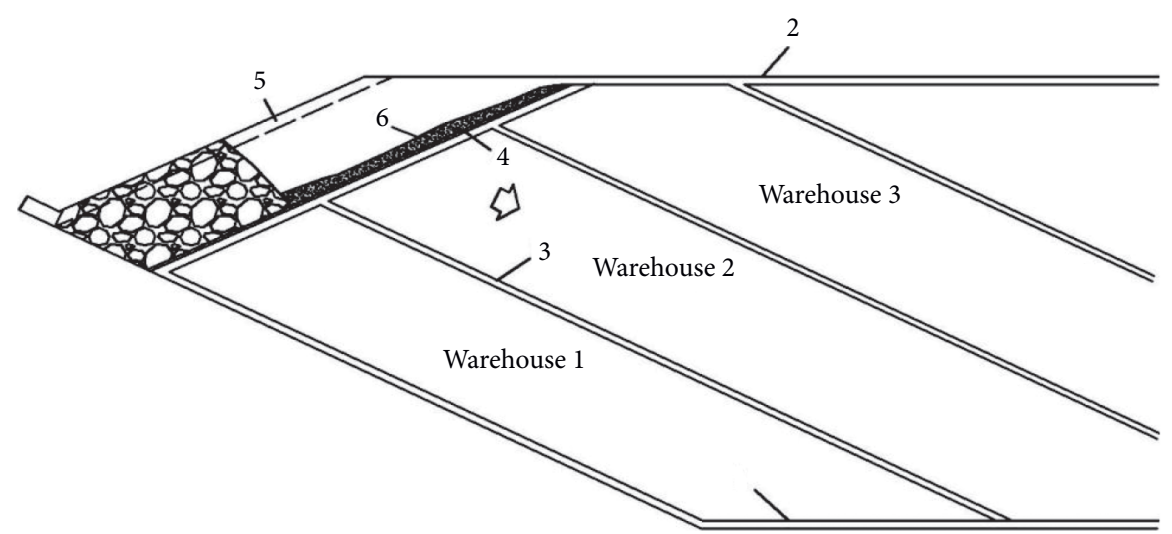

FiguRE 1: Roadway layout of sloping flexible shield support backfilling method. 1: main roadway; 2: main airway; 3: coal carrying slope; 4: working face; 5: open cut; and 6: gangue cushion.

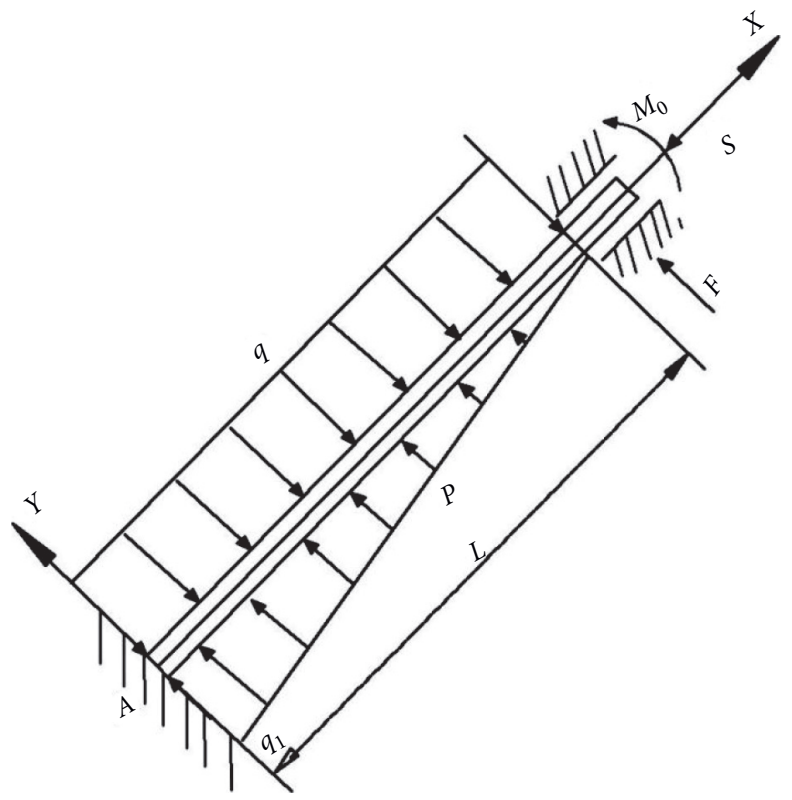

Figure 2: Mechanical model of the roof beam.

Based on the bending moment theory, the deflection differential equation of roof beam can be expressed as

$$
\begin{gathered}
y^{\prime \prime}(x)=\frac{M_{0}}{E I}+\frac{F}{E I}(L-x)-\frac{S}{E I} y(x)-\frac{q}{2 E I}(L-x)^{2} \\
+\frac{1}{E I} \int_{x}^{L} q \frac{L-\eta}{L}(\eta-x) \mathrm{d} \eta, \quad 0 \leq x \leq L .
\end{gathered}
$$

where $F, S$, and $M_{0}$ are the shear force, axial force, and bending moment. The corresponding boundary conditions are as follows:

$$
\begin{aligned}
& y(0)=0, \\
& \theta(0)=0, \\
& y(L)=0, \\
& \theta(L)=0 .
\end{aligned}
$$

The deflection equation of roof beam is given as

$$
\begin{aligned}
y(x)= & C_{1} \cos \sqrt{\frac{S}{E I}} x+C_{2} \sin \sqrt{\frac{S}{E I}} x+\left(\frac{L q-2 F}{2 S}\right) x \\
& +\frac{E I q}{L S^{2}} x-\frac{q}{6 L S} x^{3}+\frac{M_{0}}{S}+\frac{F L}{S}-\frac{L^{2} q}{3 S} .
\end{aligned}
$$

The rotation angle equation of roof beam is given as

$$
\begin{aligned}
\theta(x)= & -C_{1} \sqrt{\frac{S}{E I}} \sin \sqrt{\frac{S}{E I}} x+C_{2} \sqrt{\frac{S}{E I}} \cos \sqrt{\frac{S}{E I}} x-\frac{q}{2 L S} x^{2} \\
& +\frac{E I q}{L S^{2}}-\frac{F}{S}+\frac{L q}{2 S} .
\end{aligned}
$$

The bending moment equation of roof beam is given as 
$M=E I\left(-\frac{C_{1} S \cos \sqrt{(S / E I)} x}{E I}-\frac{C_{2} S \sin \sqrt{(S / E I)} x}{E I}-\frac{q x}{L S}\right) . \quad$ as $\quad C_{1}, C_{2}, F$, and $M_{0}$ are constant, which can be expressed

$$
\left[\begin{array}{cccc}
1 & 0 & \frac{L}{S} & \frac{1}{S} \\
0 & \sqrt{\frac{S}{E I}} & -\frac{1}{S} & 0 \\
\cos \sqrt{\frac{S}{E I}} L & \sin \sqrt{\frac{S}{E I} L} & 0 & \frac{1}{S} \\
-\sqrt{\frac{S}{E I}} \sin \sqrt{\frac{S}{E I}} L & \sqrt{\frac{S}{E I}} \cos \sqrt{\frac{S}{E I}} L & -\frac{1}{S} & 0
\end{array}\right]\left[\begin{array}{c}
C_{1} \\
C_{2} \\
F \\
M_{0}
\end{array}\right]=\left[\begin{array}{c}
\frac{L^{2} q}{3 S} \\
-\frac{E I q}{L S^{2}}-\frac{L q}{2 S} \\
\frac{E I q}{S^{2}} \\
-\frac{E I q}{L S^{2}}
\end{array}\right]
$$

$C_{1}, C_{2}, F$, and $M_{0}$ are given as

$$
\begin{aligned}
& C_{1}=\frac{\csc (L / 2) \sqrt{(S / E I)}}{12\left(L^{2} S^{3} \cos (L / 2) \sqrt{(S / E I)}\right)-2 L \sqrt{E I} S^{5 / 2} \sin (L / 2) \sqrt{(S / E I)}}\{6 E I L q \sqrt{E I S}+\sqrt{E I}\{3 L \sqrt{S}\} \\
& \cdot\left(-L^{2} q S-L^{2} q S \cos \frac{L}{2} \sqrt{\frac{S}{E I}}+2 \sqrt{E I S} L q \sin \frac{L}{2} \sqrt{\frac{S}{E I}}\right)+q L \sqrt{S}\left(-6 E I+L^{2} S\right) \\
& \left.\left.+2 q L^{3} S^{3 / 2} \cos \frac{L}{2} \sqrt{\frac{S}{E I}}-3 q L^{2} S \sqrt{E I} \sin \frac{L}{2} \sqrt{\frac{S}{E I}}\right\}\right\} \\
& C_{2}=\frac{\sqrt{E I} \sin (L / 2) \sqrt{(S / E I)}}{6 L \sqrt{E I} S^{5 / 2}(\cos L \sqrt{(S / E I)}-1)+3 L^{2} S^{3} \sin L \sqrt{(S / E I)}}\left\{3 L \sqrt{S}\left(2 L q \sqrt{E I S} \sin \frac{L}{2} \sqrt{\frac{S}{E I}}-L^{2} q S \cos \frac{L}{2} \sqrt{\frac{S}{E I}}\right)\right. \\
& \left.+2 q L^{3} S^{3 / 2} \cos \frac{L}{2} \sqrt{\frac{S}{E I}}-3 q L^{2} S \sqrt{E I} \sin \frac{L}{2} \sqrt{\frac{S}{E I}}\right\} \\
& F=\frac{\sin (L / 2) \sqrt{(S / E I)}}{6 L \sqrt{E I} S(\cos L \sqrt{(S / E I)}-1)+3 L^{2} S^{3 / 2} \sin L \sqrt{(S / E I)}}\left\{3 L \sqrt{S}\left(L^{2} q S \cos \frac{L}{2} \sqrt{\frac{S}{E I}}-2 L q \sqrt{E I S} \sin \frac{L}{2} \sqrt{\frac{S}{E I}}\right)\right. \\
& \left.+q L \sqrt{S}\left(6 E I-L^{2} S\right) \cos \frac{L}{2} \sqrt{\frac{S}{E I}}+3 q\left(L^{2} S-4 E I\right) \sqrt{E I} \sin \frac{L}{2} \sqrt{\frac{S}{E I}}\right\} \\
& M_{0}=\frac{\csc (L / 2) \sqrt{(S / E I)}}{12\left(L^{2} S^{2} \cos (L / 2) \sqrt{(S / E I)}\right)-2 L \sqrt{E I} S^{3 / 2} \sin (L / 2) \sqrt{(S / E I)}}\left\{3 L \sqrt{S}\left(4 E I q+L^{2} q S\right)+L^{2} q S \sqrt{E I}\right. \\
& \left.\cdot\left(1+\cos \frac{L}{2} \sqrt{\frac{S}{E I}}\right)-2 E I L q \sqrt{S} \sin \frac{L}{2} \sqrt{\frac{S}{E I}}+3 q\left(L^{2} S-4 E I\right) \sqrt{E I} \sin \frac{L}{2} \sqrt{\frac{S}{E I}}\right\} .
\end{aligned}
$$

3.2. Model Analysis. Take the engineering conditions of the 645 working face of the test mine as an example: the average thickness of coal seam is $2 \mathrm{~m}$, the average inclination angle is $68^{\circ}$, and the average buried depth is $520 \mathrm{~m}$. According to the engineering conditions and the mechanical experiment of specimen, the elastic modulus of roof beam is $13 \mathrm{GPa}$, the 
inertia moment of roof beam is $83 \mathrm{~m}^{4}$, the working face length is $200 \mathrm{~m}$, and the width of roof beam is $15 \mathrm{~m}$.

Considering that the model calculation is complex, the powerful advanced mathematical software MATLAB was adopted, the programs were written based on theoretical analysis, and the drawing function of the software was used. By fixing other variables, the deflection, rotation angle, and bending moment were computed, respectively.

From the results, the maximum value is $x=0.58 \mathrm{~L}$, that is, the deflection at the middle and upper part of working face, which indicates that the maximum deflection position of roof beam moves to the upper part of working face by $8 \%$ under the support of gangue filling body.

\section{Numerical Simulation Experiment}

UDEC is a numerical analysis program based on discontinuous discrete element method, which can be used to calculate the movement, deformation, and failure of surrounding rock during SDCS backfilling mining process $[24,25]$. It can well reflect the variation characteristics of stress, displacement, and failure field, and the simulation results are comprehensive, intuitive, and easy to analyze.

4.1. Model Establishment. Taking the 645 working face of the test mine as the model background, the numerical calculation model is established. The simplified coupling mathematical model has a length of $500 \mathrm{~m}$ and a height of $500 \mathrm{~m}$, which is divided into 51,756 units. The numerical calculation model is simplified into a structure of 7 rock layers for research. In this simulation, the gangue is used as the filling material to fill the goaf. According to the properties of gangue filling body, the recovery rate of working face, and field experience, the mechanical parameters of gangue are determined, and the mechanical parameters of each rock layer material selected by numerical model are shown in Table 1.

In the simulation, the Mohr-Coulomb yield criterion is used to judge the failure of rock mass. Because of the nonlinear stress-strain characteristics of the gangue, the double-yield criterion with the hardening process is selected to model the gangue filling body. The horizontal gradient stress of $3 \mathrm{MPa}$ is set on the model, and the vertical pressure of $5 \mathrm{MPa}$ is applied on the upper boundary to simulate the rock pressure at a height of $200 \mathrm{~m}$.

The model adopts the step-by-step excavations, and each step is $40 \mathrm{~m}$ along the vertical direction of coal seam with a total of 5 steps being excavated. Two situations of caving as well as backfilling are simulated, respectively. In the backfilling method simulation, the goaf is filled by certain time steps after coal seam is excavated, the Mohr-Coulomb model of filling body is transformed into the strain softening model, and the model parameters are reduced. For the two methods of caving as well as backfilling, the migration law of overlying strata is analyzed from three aspects: the movement, deformation, and failure law of surrounding rock as well as the variation characteristics of stope stress.

\subsection{Results Analysis}

4.2.1. Displacement of Surrounding Rock. The horizontal displacement cloud chart of surrounding rock mined by caving as well as backfilling method is shown in Figures 3-6. The colored contour represents the roof displacement along the $X$-direction. For example, in Figure 3 , the roof displacement was $-0.008 \mathrm{~m}$ in the purple area and $-0.006 \mathrm{~m}$ in the red area.

Compared with the simulation results of caving as well as the backfilling method, it can be seen that when the stope height is $40 \mathrm{~m}$ and the caving method is used, because the exposed area of surrounding rock is small, the movement of immediate roof and immediate floor is small, and only a small number of cracks appear; the horizontal displacement of immediate roof is $53 \mathrm{~mm}$, while it is $24 \mathrm{~mm}$ for the immediate floor; the overlying strata slightly subside, and the maximum subsidence occurs directly above the goaf, with the maximum value of $243 \mathrm{~mm}$. When the backfilling method is adopted, the horizontal displacement of immediate roof is $50 \mathrm{~mm}$, while it is $21 \mathrm{~mm}$ for the immediate floor, and the maximum subsidence is $235 \mathrm{~mm}$, which is basically the same as that of caving. There are fissure zones on the immediate roof using caving method with a height of $8 \mathrm{~m}$, while the height using backfilling method is $5 \mathrm{~m}$.

When the stope height increases to $80 \mathrm{~m}$, the horizontal displacement of roof and floor will increase, but the growth rate of the roof is faster. The horizontal displacement value of which using caving method is $117 \mathrm{~mm}$, while the value of roof using backfilling method is $92 \mathrm{~mm}$. In the caving method, the roof was separated and extended to the main roof, and the height of the fracture zone expanded to $19 \mathrm{~m}$. However, after the use of gangue backfilling method, the roof separation has increased, but the height of the fracture zone is only $7 \mathrm{~m}$.

When the model excavation is increased to $120 \mathrm{~m}$, the displacement of roof and floor continues to increase. During caving mining, the horizontal displacement values are unevenly distributed along the inclined direction of strata, the deformation of the upper and middle roof is greater than that of the lower, and the maximum deformation of floor is close to the middle of goaf, resulting in slight floor heave of the immediate floor; plastic failure of the immediate roof occurred in the upper central of goaf, and the horizontal deformation increased sharply to a maximum of $174 \mathrm{~mm}$. During gangue backfilling mining, large deformation of upper roof occurred in goaf, and the largest horizontal deformation is $151 \mathrm{~mm}$ with no bottom drum.

When the height of the stope reaches $200 \mathrm{~m}$, during caving mining, the maximum horizontal deformation of roof reaches $560 \mathrm{~mm}$, the maximum subsidence of overlying strata is $682 \mathrm{~mm}$, and the development height for the roof fracture zone reaches $153 \mathrm{~m}$. When the backfilling method is adopted, the horizontal deformation of roof is only $277 \mathrm{~mm}$, and the subsidence of overlying strata is controlled at $353 \mathrm{~mm}$. After the completion of model excavation, the displacement and deformation of surrounding rock of the two mining methods are compared. The maximum horizontal displacement and subsidence curves are shown in Figures 7 and 8. 
TABLE 1: Mechanical properties of rock parameters of the numerical model.

\begin{tabular}{|c|c|c|c|c|c|c|c|}
\hline Lithology & $\begin{array}{l}\text { Thickness } \\
(\mathrm{m})\end{array}$ & $\begin{array}{l}\text { Bulk density } \\
\left(\mathrm{kg} \cdot \mathrm{m}^{-3}\right)\end{array}$ & $\begin{array}{l}\text { Elastic modulus } \\
\qquad(\mathrm{GPa})\end{array}$ & $\begin{array}{l}\text { Poisson's } \\
\text { ratio }\end{array}$ & $\begin{array}{l}\text { Tensile strength } \\
(\mathrm{MPa})\end{array}$ & $\begin{array}{c}\text { Cohesion } \\
(\mathrm{MPa})\end{array}$ & $\begin{array}{c}\text { Friction angle } \\
\left(\left(^{\circ}\right)\right.\end{array}$ \\
\hline $\begin{array}{l}\text { Siltstone } \\
\text { interbedding }\end{array}$ & 100 & 2650 & 9.3 & 0.25 & 10.2 & 11.3 & 36 \\
\hline Main roof siltstone & 14 & 2700 & 8.1 & 0.24 & 8.6 & 5.3 & 35 \\
\hline $\begin{array}{l}\text { Immediate roof } \\
\text { siltstone }\end{array}$ & 4 & 2650 & 7.5 & 0.24 & 6.0 & 3.4 & 33 \\
\hline Coal & 2 & 1780 & 4.2 & 0.32 & 2.1 & 1.5 & 24 \\
\hline $\begin{array}{l}\text { Immediate floor } \\
\text { siltstone }\end{array}$ & 8 & 2620 & 6.8 & 0.25 & 7.4 & 2.0 & 34 \\
\hline Main floor siltstone & 20 & 2670 & 8.2 & 0.23 & 9.4 & 3.0 & 35 \\
\hline $\begin{array}{l}\text { Diabase } \\
\text { interbedding }\end{array}$ & 100 & 2720 & 13.4 & 0.22 & 13.1 & 4.0 & 37 \\
\hline Waste rock & 1.8 & 2000 & 0.5 & 0.37 & 0.1 & 0.2 & 15 \\
\hline Joint parameters & - & - & 0.7 & 0.36 & 2 & 1 & 22 \\
\hline
\end{tabular}

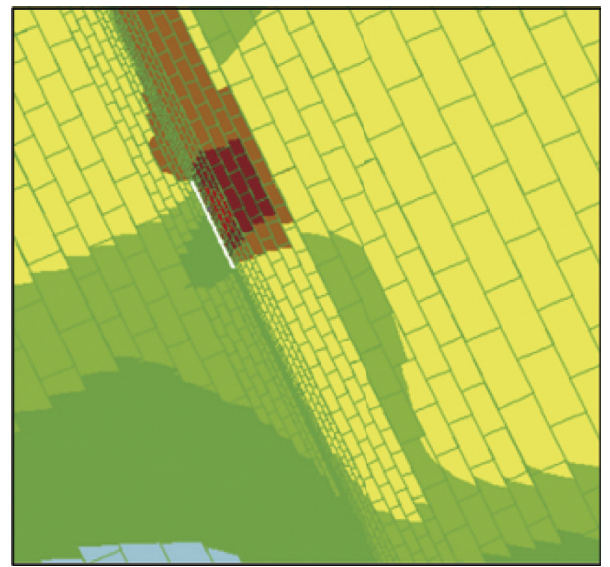

(a)

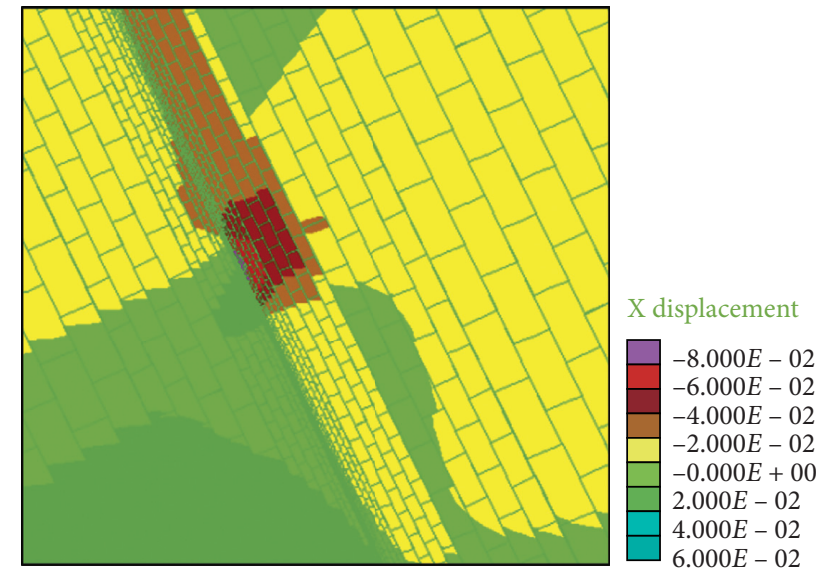

(b)

FIgURE 3: Horizontal displacement contours of surrounding rock with $40 \mathrm{~m}$ stope height. (a) Caving. (b) Backfilling.

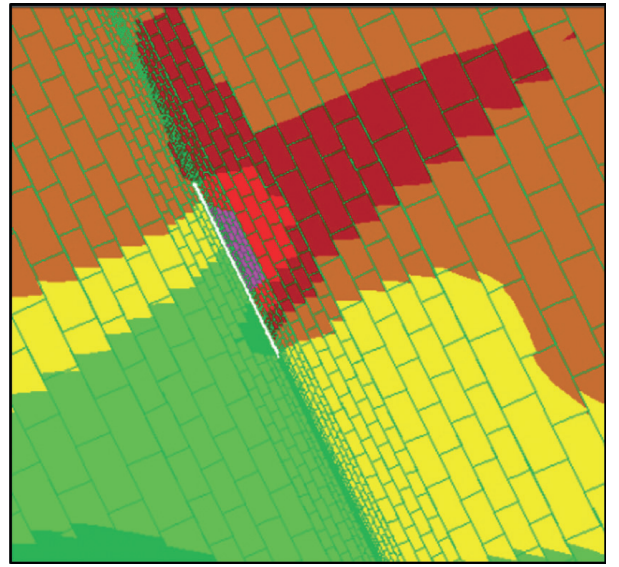

(a)

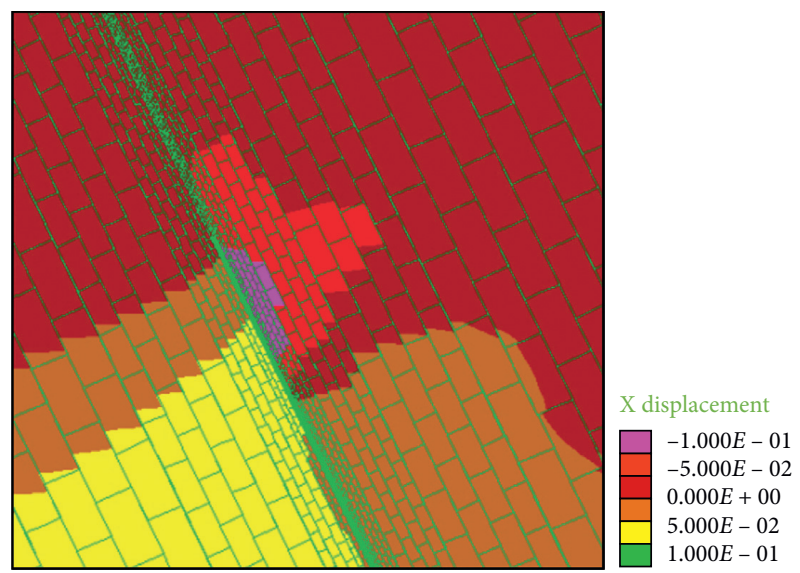

(b)

FIgURE 4: Horizontal displacement contours of surrounding rock with $80 \mathrm{~m}$ stope height. (a) Caving. (b) Backfilling.

It can be seen from Figures 7 and 8 that the displacement of surrounding rock in SDCS caving mining presents three stages of steady growth-rapid growth-tends to be stable. In the initial mining stage, the maximum horizontal and vertical displacement increase gently. The first inflection point of subsidence curve appears at the height of $100 \mathrm{~m}$, and the second inflection point appears at $180 \mathrm{~m}$. The subsidence increases rapidly between the two inflection points, the 


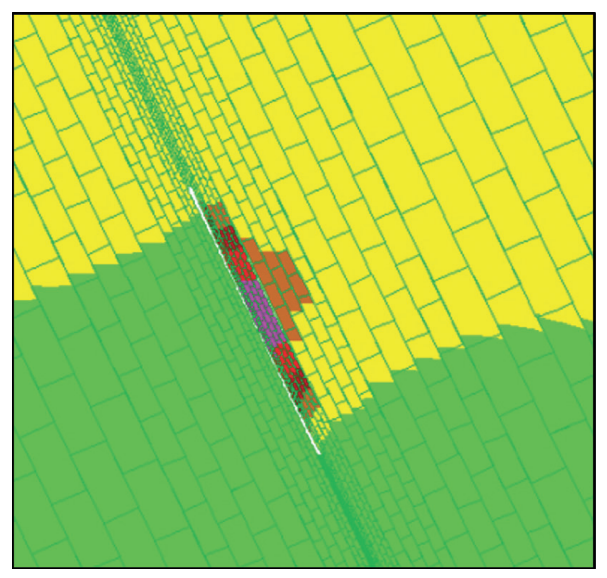

(a)

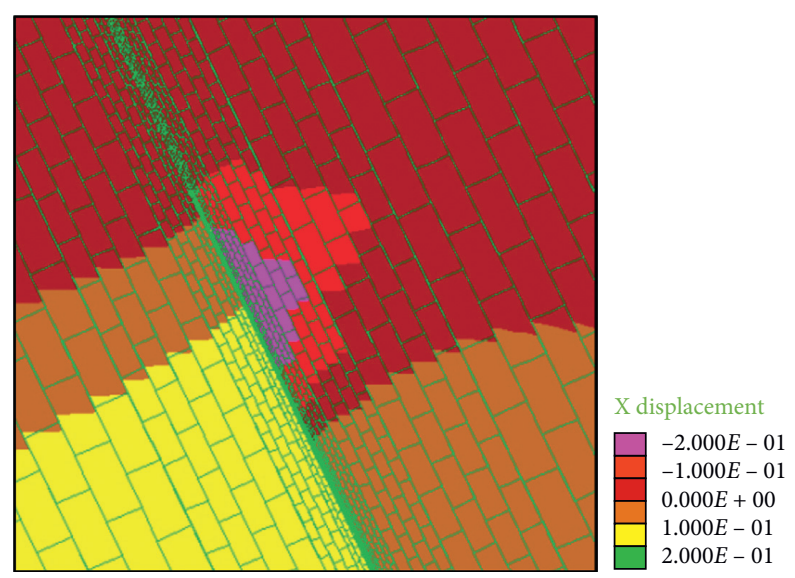

(b)

FIGURE 5: Horizontal displacement contours of surrounding rock with $120 \mathrm{~m}$ stope height. (a) Caving. (b) Backfilling.

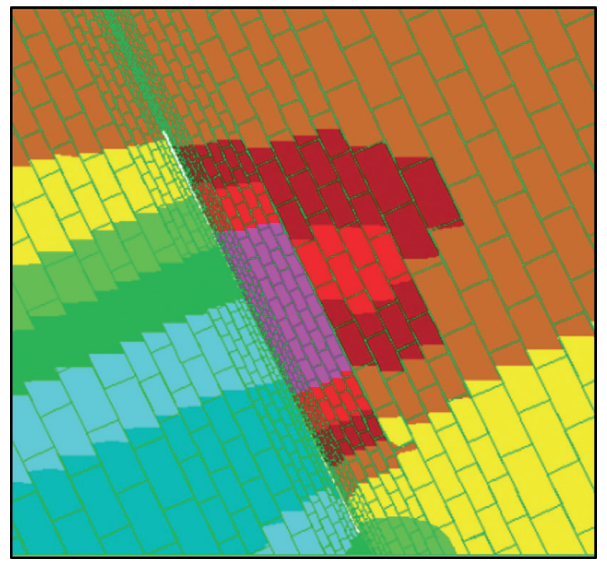

(a)

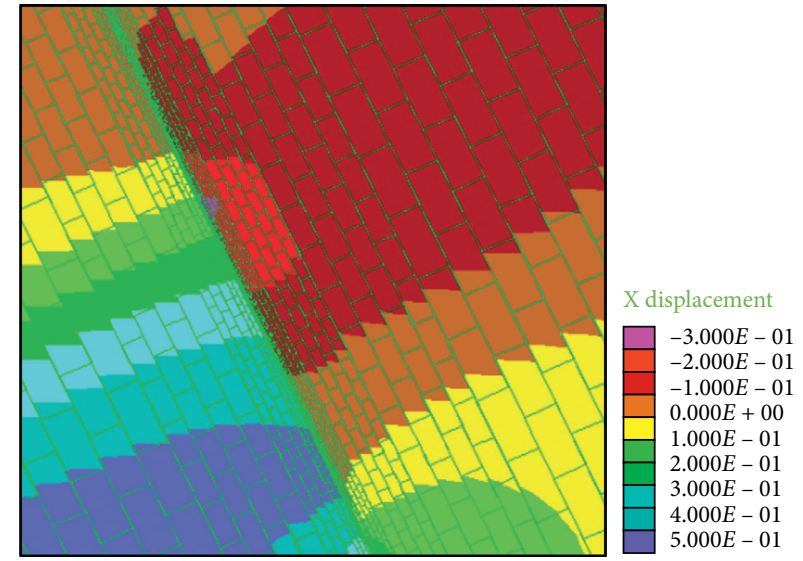

(b)

Figure 6: Horizontal displacement contours of surrounding rock with $200 \mathrm{~m}$ stope height. (a) Caving. (b) Backfilling.

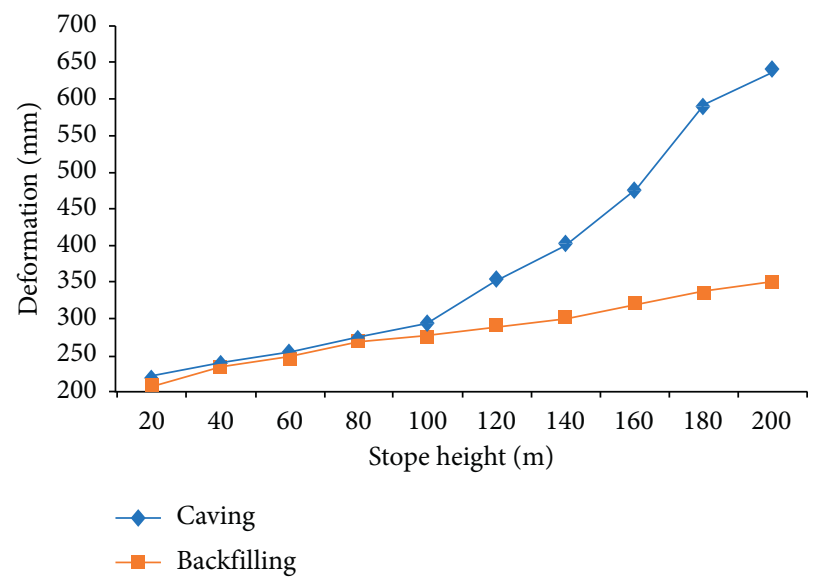

FIgURE 7: The maximum subsidence contrast graph.

growth slows down when reaching the second inflection point, and the maximum subsidence is $642 \mathrm{~mm}$. The two inflection points of horizontal displacement appear at $120 \mathrm{~m}$ and $160 \mathrm{~m}$, and the horizontal displacement increases from
$174 \mathrm{~mm}$ to $461 \mathrm{~mm}$. It can be seen that the surrounding rocks move and deform violently in this mining process, which may have certain impacts on the roadway and working face, and then tend to moderate. 


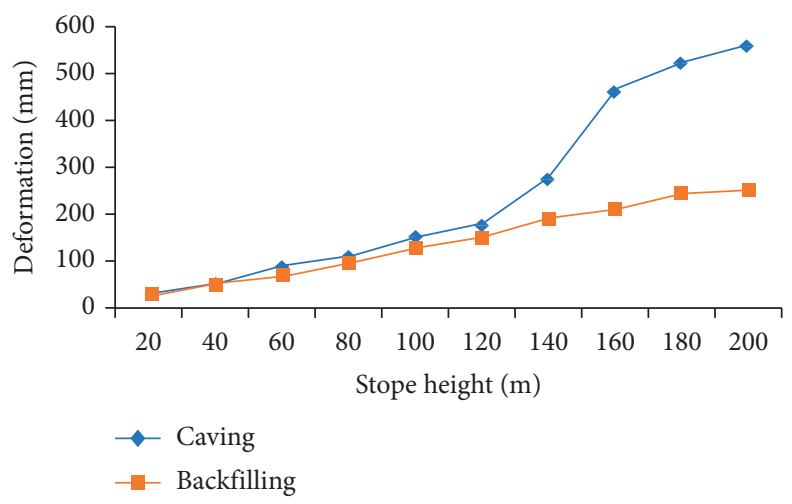

FIgURE 8: The maximum horizontal displacement comparison graph.

From the backfilling mining movement and deformation curve of surrounding rock, it can be seen that the increase of the maximum horizontal deformation and subsidence value are relatively gentle, and there are no sudden increases, which indicates that the unbalanced stress caused by mining is slowly released under the support of gangue filling body. The horizontal deformation value and subsidence value are $247 \mathrm{~mm}$ and $353 \mathrm{~mm}$, respectively, which are $55.9 \%$ and $45 \%$ lower than those of the caving mining. Therefore, the ability of backfilling method to control the horizontal movement of surrounding rock is more prominent.

4.2.2. Variation of the Stope Stress. Figures 9-14 show the distributions of vertical and horizontal stresses with the colored lines representing different degrees of stresses. For example, in Figure 10, the negative values indicate that the stress is along the downward direction, where purple lines suggest the stress impact range of $16 \mathrm{MPa}$ and the red lines suggest the stress impact range of $14 \mathrm{MPa}$.

It is demonstrated in Figures 9 and 10 that the stope stress distribution with the backfilling method is basically the same as that of the caving method in the early stage. The maximum horizontal stress appears on the side of the unmined coal pillar at the bottom of goaf, which is $6.7 \mathrm{MPa}$ (Figure 9(b)) and 6.8 MPa (Figure 9(a)), respectively, and the maximum vertical stress appears in the lower part of the goaf, which is $14.6 \mathrm{MPa}$ (Figure $10(\mathrm{~b})$ ) and $15.3 \mathrm{MPa}$ (Figure 10(a)), respectively. The deformation of surrounding rock along the normal direction of the coal seam is less after mining, the filling body is gradually compressed (but not fully compacted), and the strength is not enough to support the roof and floor. Therefore, the stope stress distribution will not be affected, and the filling area is still in the stress unloading area.

The horizontal and vertical stresses of the surrounding rock increase with the increase of stope height. When the advancing height of working face reaches $110 \mathrm{~m}$, the compressive stress of overlying strata perpendicular to the plane direction is transferred to the floor strata after the filling gangue is gradually compacted by roof, and the stope stress distribution using the backfilling method changes gradually. At this time, the stress in the filling area rises and forms a stress recovery zone. The filling gangue gradually supports the roof and shares the compressive stress of overlying strata borne by the unmined coal pillar as well as transferring the stress of surrounding rock partially. Therefore, the degree and range of stress concentration are reduced. The maximum vertical stress of the backfilling mining is $18.5 \mathrm{MPa}$, which is located in the rock layer on the side of floor in the middle of the goaf. The position is far away from the working face and has little impacts on mining operations, as shown in Figure 11(b). The maximum vertical stress using the caving method appears on the bottom pillar, which is $21.3 \mathrm{MPa}$, and the stress concentration factor is 1.78 , which is 1.17 times of that of the backfilling method. It has greater impacts on the working face and roadway, as shown in Figure 11(a).

As the model continues to be excavated, the stress unloading area using the caving method gradually expands, and the stress concentration appears in the unmined pillar. When the coal seam mining height reaches $160 \mathrm{~m}$, the horizontal stress distribution of the surrounding rock is shown in Figure 12. During the caving mining, the unmined pillar in the lower part of goaf shows stress concentrations, the horizontal stress increases to $15.2 \mathrm{MPa}$, and the stress concentration factor is 2.53 . The horizontal stress of the surrounding rock using backfilling method is $13.1 \mathrm{MPa}$, and the stress concentration is reduced by $13.8 \%$ compared with the caving method.

The stress value of the surrounding rock using the caving method increases rapidly with the advancement of the working face. When the stope height reaches $200 \mathrm{~m}$, the stress concentration degree increases significantly, as shown in Figures 13(a) and 14(a); the vertical stress on the roof side of the lower pillar increased sharply, which is $29 \mathrm{MPa}$, and the stress concentration factor reached the maximum 2.42; the horizontal stress appears at the roof side of lower pillar, which reaches a peak value of $18.7 \mathrm{MPa}$. During backfilling method, the stress of the surrounding rock behind working face shows an overall upward trend with small increase, and the stress concentration is greatly reduced; the maximum vertical stress of surrounding rock reaches $23.7 \mathrm{MPa}$; with the further compaction of gangue filling body, the range of stress recovery area is gradually expanded, the maximum horizontal stress is reduced to $10.8 \mathrm{MPa}$, and the degree of stress concentration is further eased, as shown in 


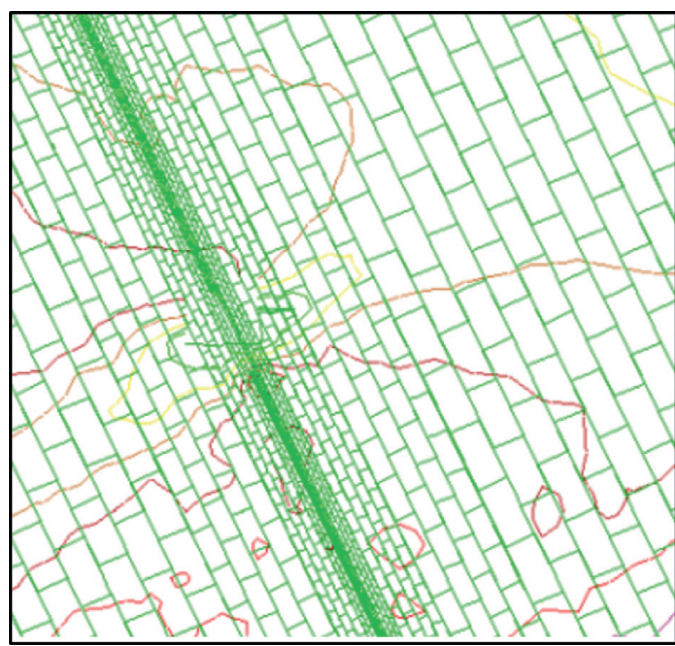

XX stress
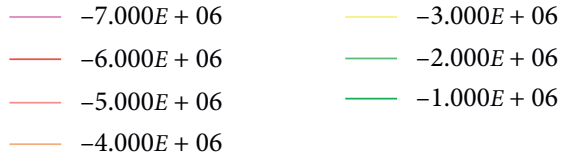

(a)

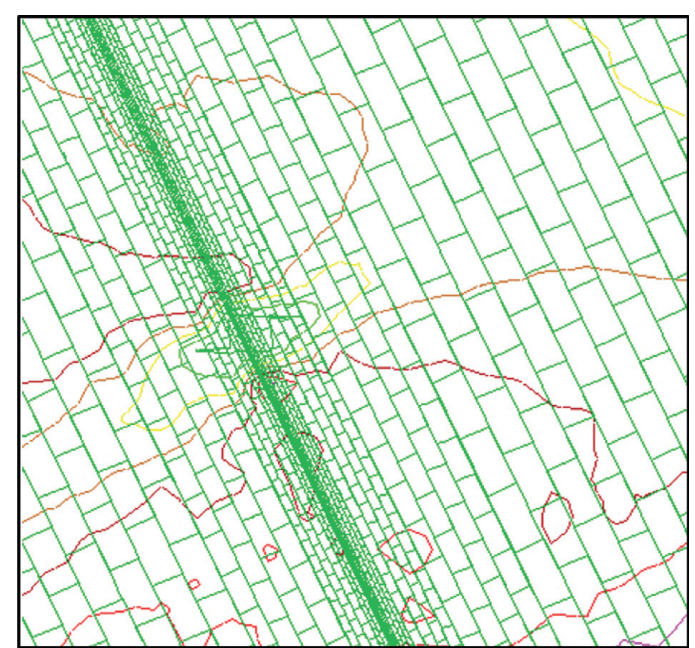

XX stress

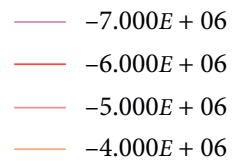

$-4.000 E+06$

(b)

FIgURE 9: Surrounding rock horizontal stress distribution with $40 \mathrm{~m}$ stope height. (a) Caving. (b) Backfilling.

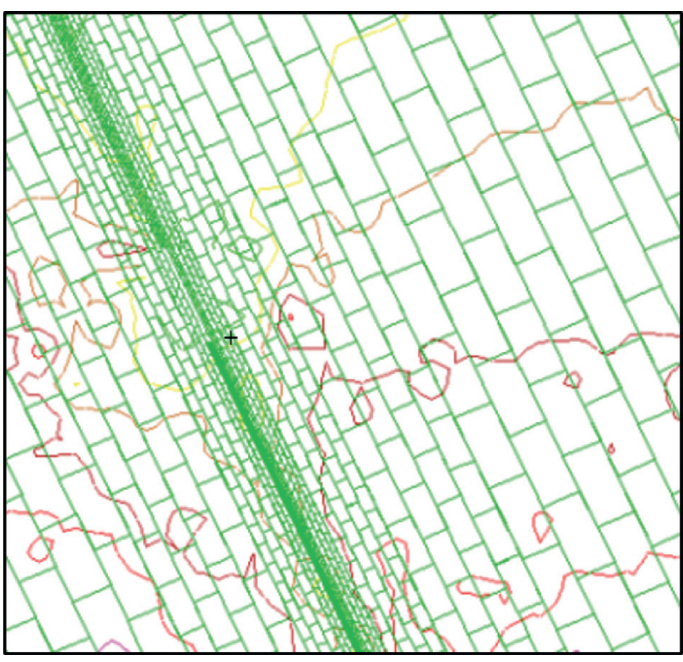

XX stress
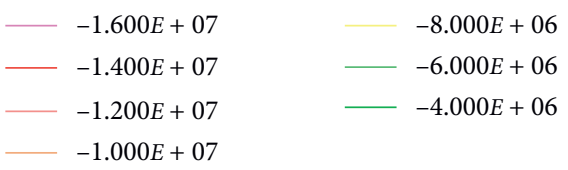

(a)

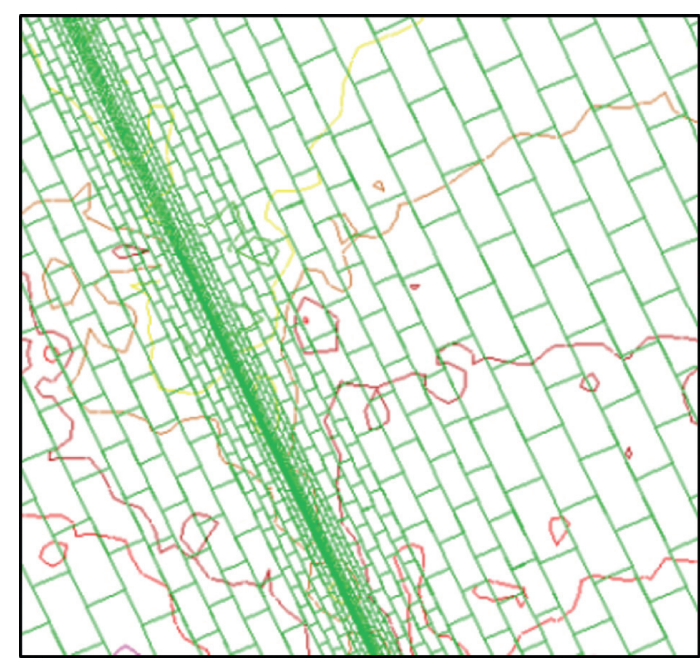

YY stress

$-1.600 E+07$
$-1.400 E+07$
$-\quad-1.200 E+07$
$-1.000 E+07$

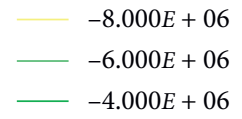

(b)

FIGURE 10: Surrounding rock vertical stress distribution with $40 \mathrm{~m}$ stope height. (a) Caving. (b) Backfilling.

Figures 13(b) and 14(b). The vertical stress of roadway roof reaches $39.1 \mathrm{MPa}$ using caving method, while that using gangue backfilling method is only $21.4 \mathrm{MPa}$, which decreases by $44 \%$. The stress concentration degree and influence scope are obviously reduced, and the stress environment of roadway is obviously improved. 

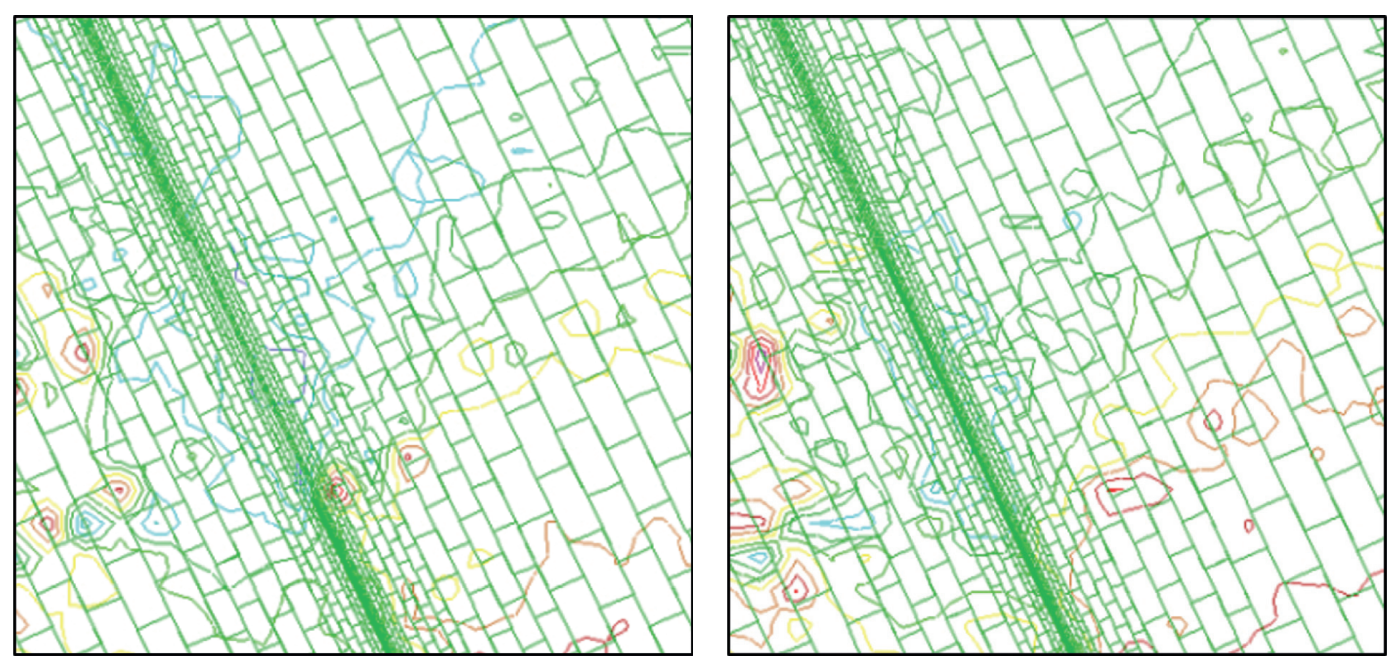

YY stress

YY stress

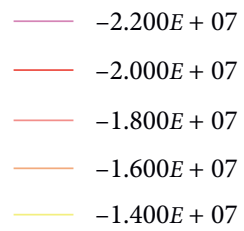

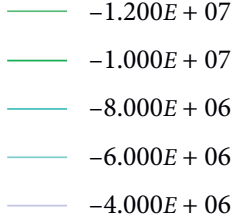

(a)

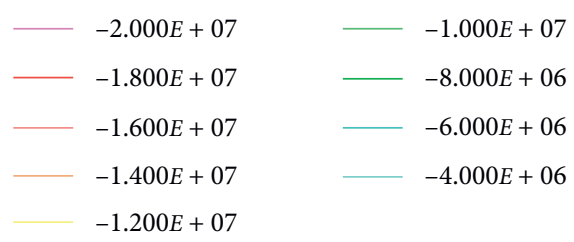

(b)

FIGURE 11: Surrounding rock vertical stress distribution with $110 \mathrm{~m}$ stope height. (a) Caving. (b) Backfilling.

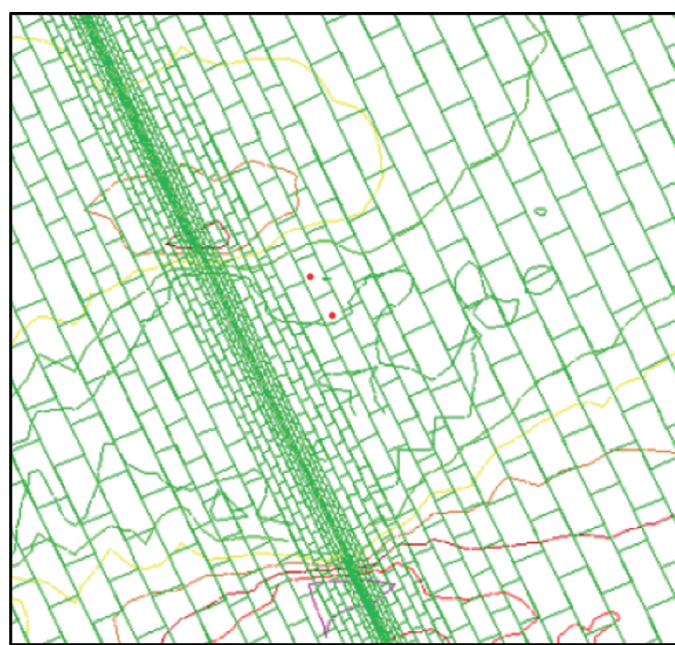

XX stress

$$
\begin{array}{r}
-1.600 E+07 \\
--1.400 E+07 \\
--1.200 E+07 \\
-1.000 E+07
\end{array}
$$

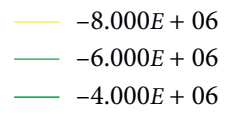

(a)

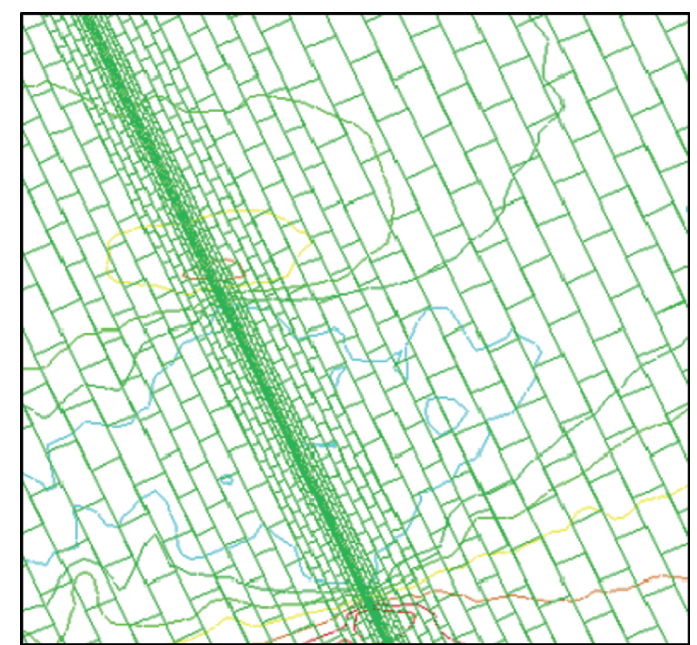

$$
\begin{aligned}
& \text { XX stress } \\
& -1.400 E+07 \\
& -1.200 E+07 \\
& -1.000 E+07 \\
& -8.000 E+06
\end{aligned}
$$

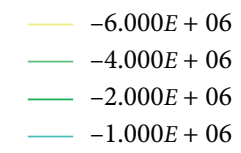

(b)

FIGURE 12: Surrounding rock horizontal stress distribution with $160 \mathrm{~m}$ stope height. (a) Caving. (b) Backfilling.

4.2.3. Failure Law of Surrounding Rock. The failure cloud chart of surrounding rock mined by caving as well as backfilling method is shown in Figures 15-18. The red stars indicate the plastic yield faces, the green crosses show the history yield, and the purple circles represent the tensile failures. 


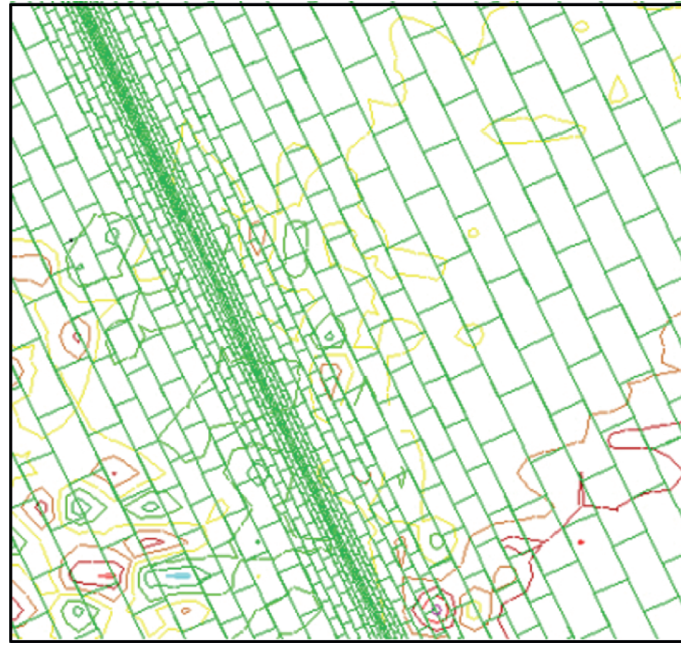

YY stress

$-3.000 E+07$

$-2.500 E+07$

$-2.000 E+07$

$-1.500 E+07$

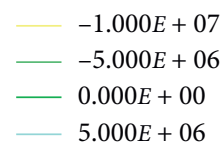

(a)

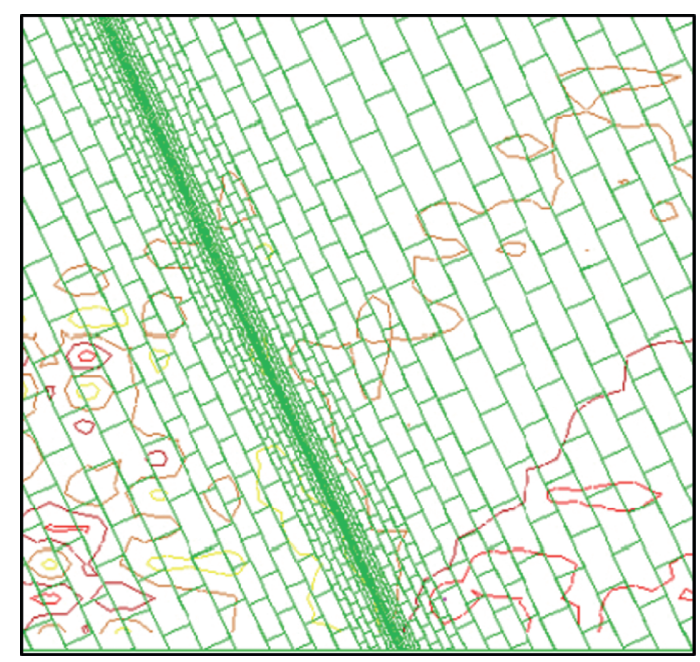

YY stress
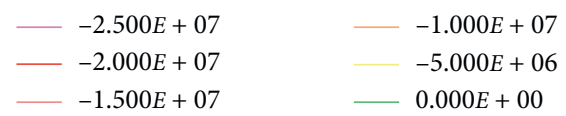

(b)

Figure 13: Surrounding rock vertical stress distribution with $200 \mathrm{~m}$ stope height. (a) Caving. (b) Backfilling.

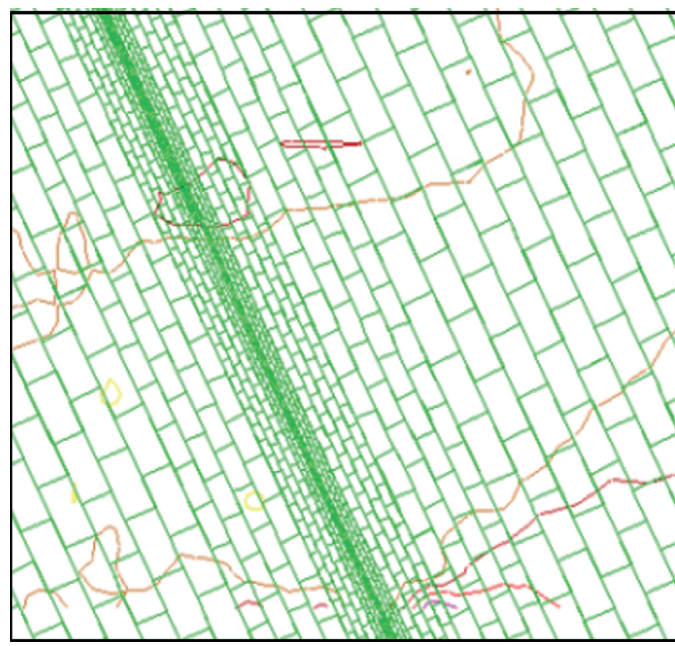

XX stress

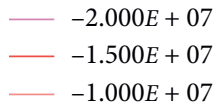

$$
\begin{aligned}
& -5.000 E+06 \\
& 0.000 E+00
\end{aligned}
$$

(a)

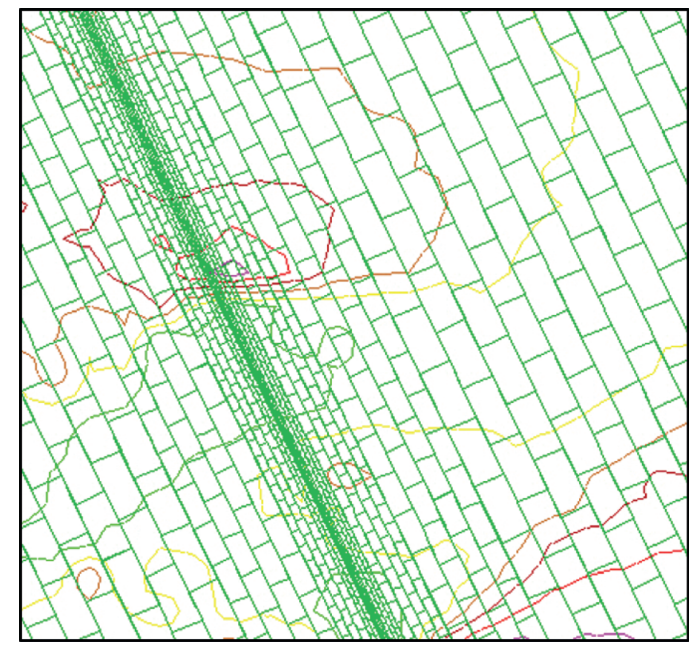

$$
\begin{aligned}
& \text { XX stress } \\
& -\quad-1.200 E+07 \\
& -1.000 E+07 \\
& -\quad-8.000 E+06
\end{aligned}
$$

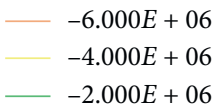

(b)

FIGURE 14: Surrounding rock horizontal stress distribution with $200 \mathrm{~m}$ stope height. (a) Caving. (b) Backfilling.

As shown in Figures 15-18, early on in the cave mining, relatively small plastic zones can occur at the upper and lower the unmined coal pillars. As the stope height increases, the damage zones of the unmined coal pillars develop gradually upward and downward; failure occurs at the roof in the middle of the goaf when the stope reaches $120 \mathrm{~m}$; evident damage takes place at the roof when the stope height increases to $160 \mathrm{~m}$ and it keeps developing toward the main roof; when the stope height is $200 \mathrm{~m}$, wedge-shaped plastic zones are mainly in the roof of the goaf middle, with a height of $143 \mathrm{~m}$. Meanwhile, large plastic failure can be observed for the immediate roof of the goaf lower section, and tensile failure occurs between the immediate and main roofs. 


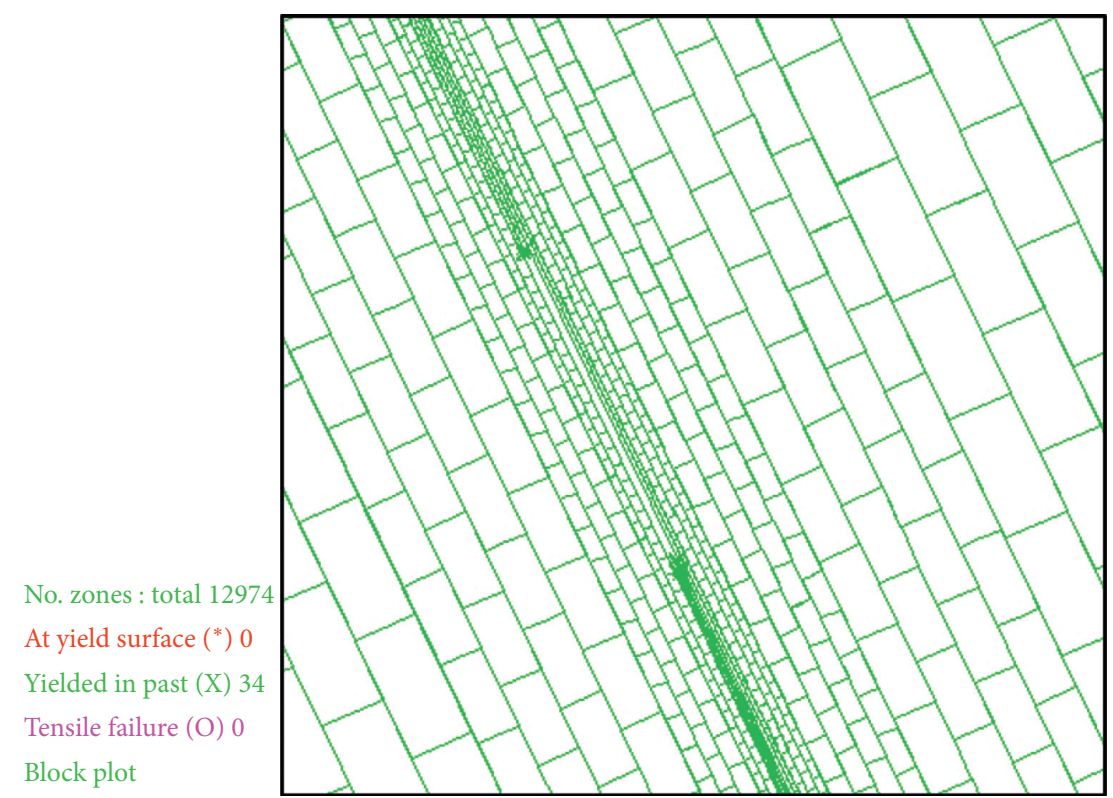

FIGURE 15: Surrounding rock failure pattern with $80 \mathrm{~m}$ stope height (caving method).

No. zones : total 15938

At yield surface $\left(^{*}\right) 0$

Yielded in past (X) 41

Tensile failure $(\mathrm{O}) 0$

Block plot

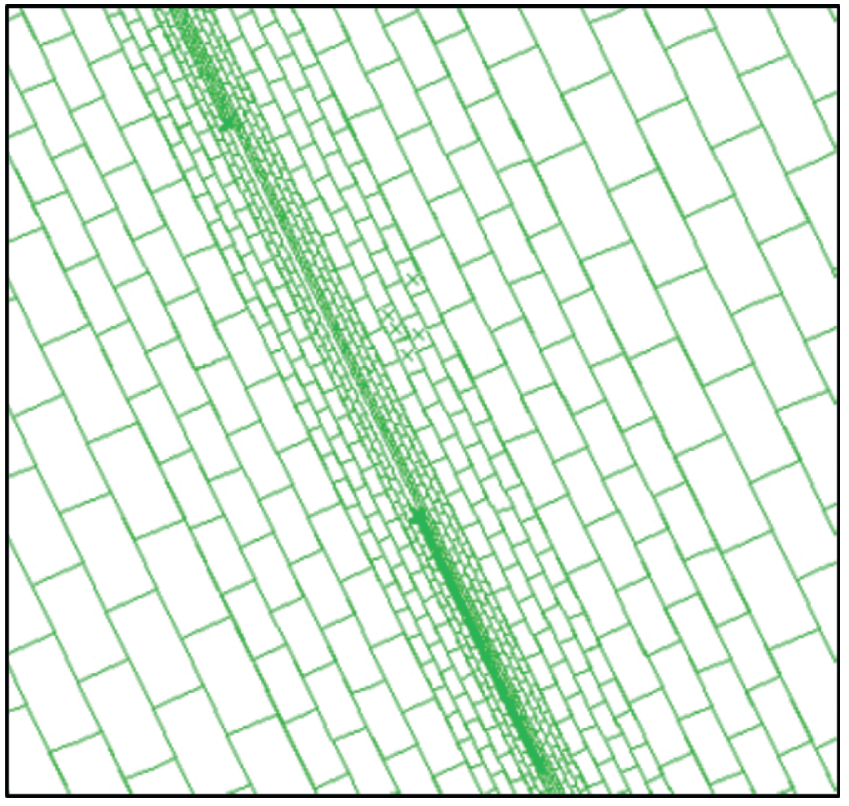

FIGURE 16: Surrounding rock failure pattern with $120 \mathrm{~m}$ stope height (caving method).

When the backfilling technique is used, the goaf roof only demonstrates bending deformation with no obvious failure, except for the minor damage when the stope height is $160 \mathrm{~m}$; the damage zones evolve toward the main roof, and the overall stope shows outstanding stability.

\section{Physical Similarity Simulation Experiment}

5.1. Experimental Scheme. The physical and mechanical parameters based on the 645 working face of the experimental coal mine are shown in Table 2.
The plane stress model is used to reflect the distribution state and the change trend of rock stress in the mining process. The measuring base points are laid in the rock strata of working face, which is arranged in a grid shape, 9 in the floor rock strata and 18 in the roof rock strata, with an average interval of $10 \mathrm{~cm} \times 10 \mathrm{~cm}$. To measure the migration of the overlying strata, the displacement base points are set up more accurately in different strata on the front of model, which are arranged in 11 layers along the coal seam, $10 \mathrm{~cm} \times 10 \mathrm{~cm}$ grid arrangement, each layer of 9 basis points, and a total of 99 displacement bases. The simulated model is excavated 


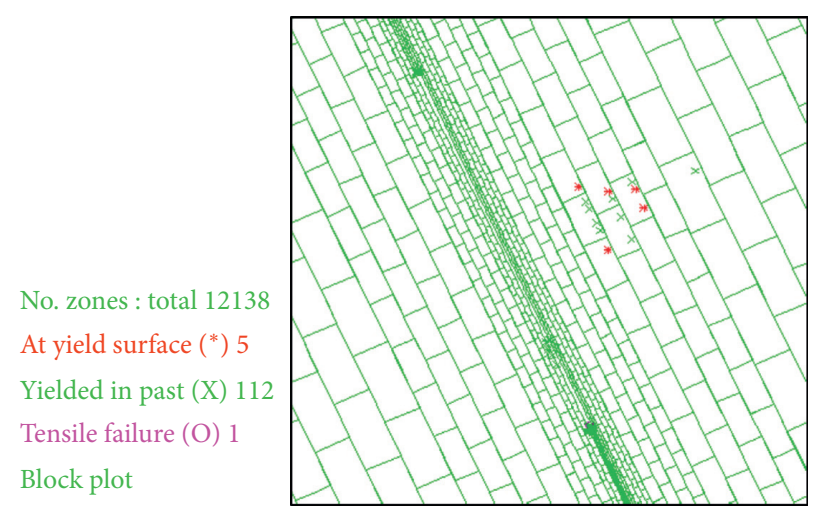

(a)

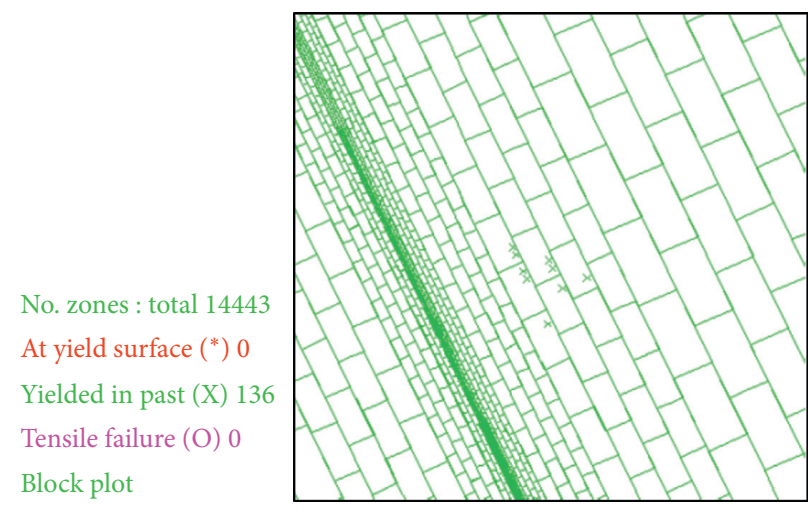

(b)

FIGURE 17: Surrounding rock failure pattern with $160 \mathrm{~m}$ stope height. (a) Caving. (b) Backfilling.

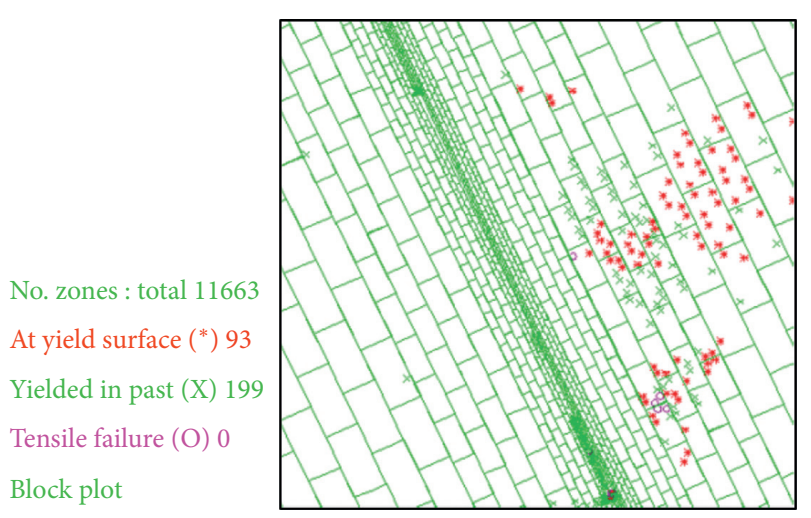

(a)

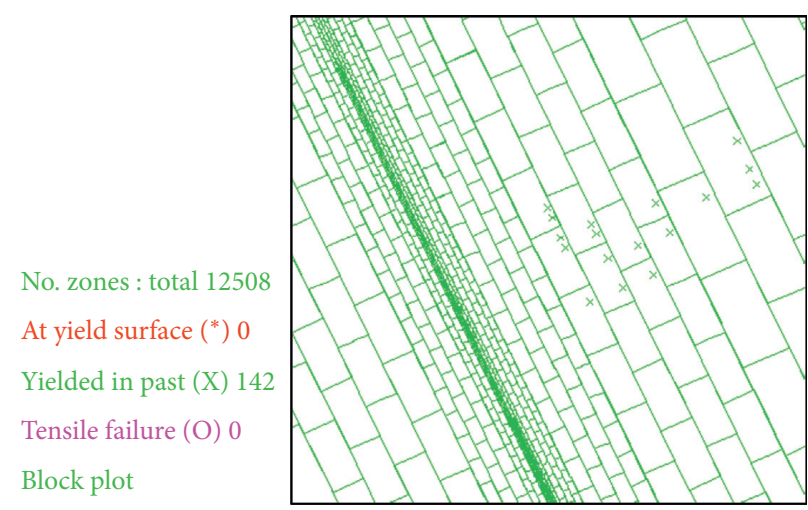

(b)

FIGURE 18: Surrounding rock failure pattern with $200 \mathrm{~m}$ stope height. (a) Caving. (b) Backfilling.

TABLE 2: The strata physical and mechanical parameters.

\begin{tabular}{lccc}
\hline Lithology & Thickness $(\mathrm{m})$ & Compressive strength $\left(\mathrm{kg} / \mathrm{cm}^{2}\right)$ & Bulk density $\left(\mathrm{kg} \cdot \mathrm{m}^{-3}\right)$ \\
\hline Main roof siltstone & 14 & 918 & 2700 \\
Immediate roof siltstone & 4 & 734 & 2650 \\
Coal & 2 & 208 & 1780 \\
Immediate floor siltstone & 8 & 758 & 2620 \\
Main floor siltstone & 20 & 1050 & 2670 \\
\hline
\end{tabular}

with a vertical mining height of $4 \mathrm{~cm}$. After each excavation of the coal body, the roof and floor stress and strain will be monitored after putting the filling material into the goaf. The EPS polystyrene foam board has the characteristics of low density and weak antiextrusion performance, which is selected as the filling material to simulate the mechanical characteristics of filling body.

\subsection{Analysis of Experimental Results}

5.2.1. Analysis of Displacement Observation. The movement and deformation of surrounding rock in different stages of SDCS backfill mining are simulated, as shown in Figure 19.

When the stope height reaches $10 \mathrm{~m}$, the roof and floor are not significantly deformed. When the stope height reaches
$20 \mathrm{~m}$, the bending deformation occurs directly on the top of the goaf, the height of the fissure zone is $3 \mathrm{~m}$, the length of the lowermost end is $16 \mathrm{~m}$, the uppermost end is $4 \mathrm{~m}$, and the moving amount of roof is $4 \mathrm{~mm}$. The surrounding rock movement is shown in Figures 19(a) and 19(b).

With the excavation of the working face, the displacement of roof strata gradually expands. When the stope height reaches $26 \mathrm{~m}$, the deformation of the immediate roof increases, the fracture occurs, the fracture angle is about $70^{\circ}$, and the roof movement expands to $11 \mathrm{~mm}$, as shown in Figure 19(c). When the stope height reaches $30 \mathrm{~m}$, the separation layer develops to the main roof, the fracture length reaches $27 \mathrm{~m}$, and the compression of filling body reaches $31 \mathrm{~mm}$, as shown in Figure 19(d). When the stope height reaches $36 \mathrm{~m}$, the height of the fracture zone is $14 \mathrm{~m}$, the maximum fracture 


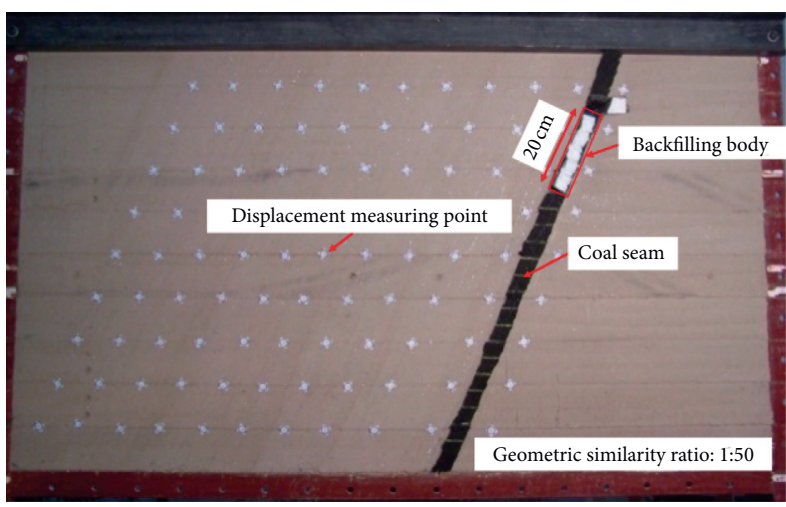

(a)

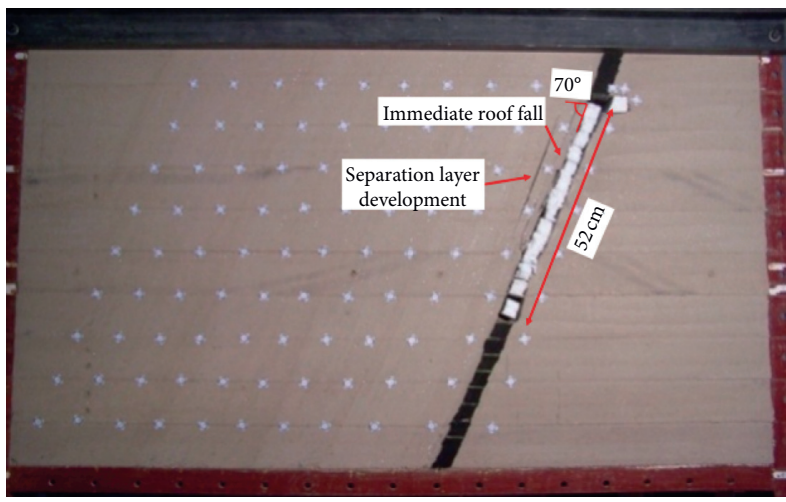

(c)

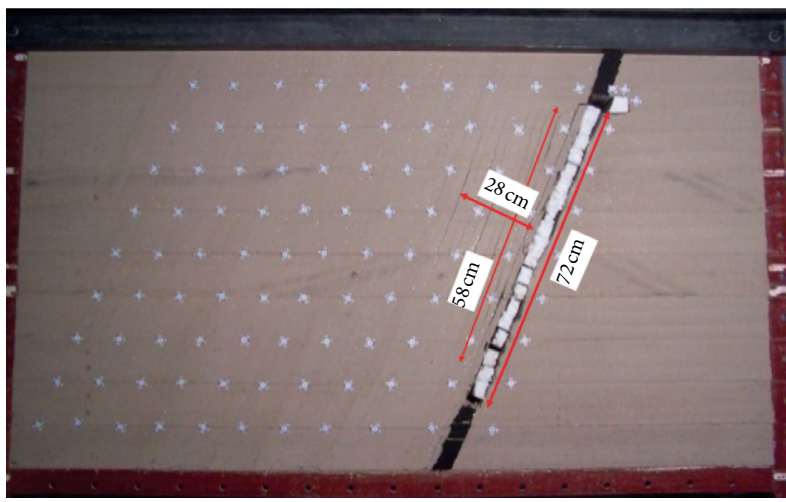

(e)

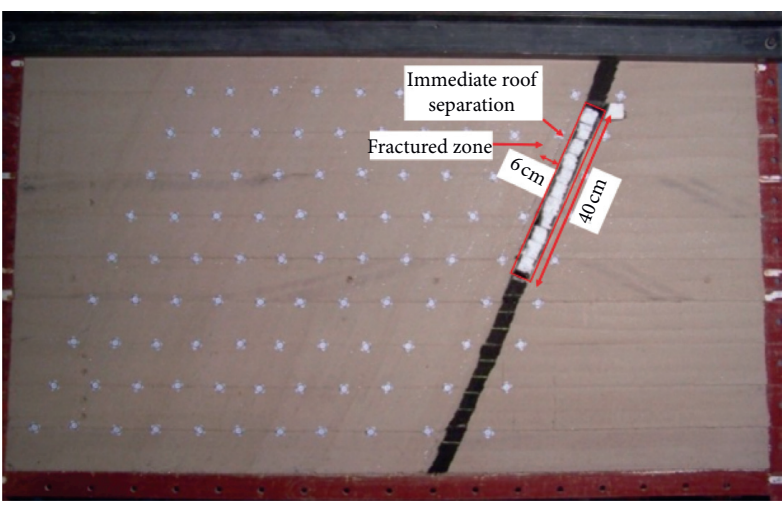

(b)

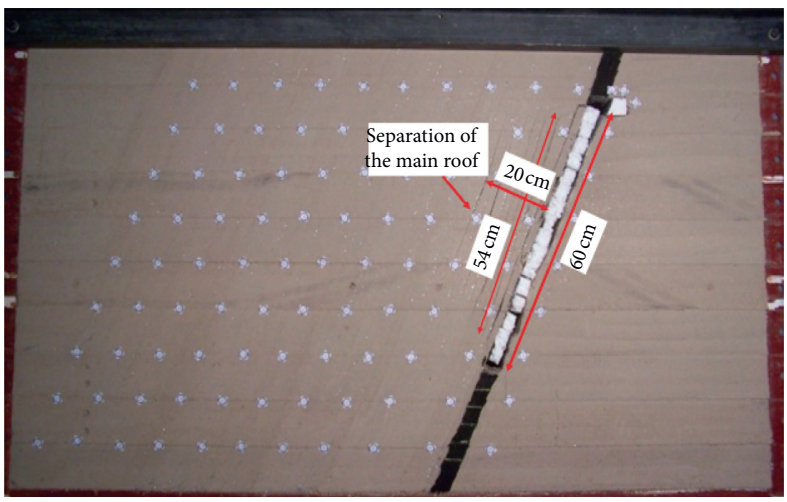

(d)

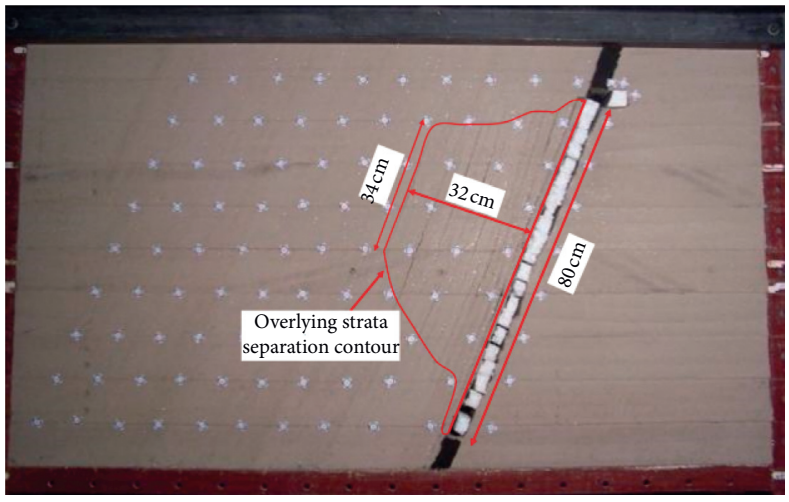

(f)

Figure 19: Surrounding rock movement and deformation of each mining stages. (a) $10 \mathrm{~m}$. (b) $20 \mathrm{~m}$. (c) $26 \mathrm{~m}$. (d) $30 \mathrm{~m}$. (e) $36 \mathrm{~m}$. (f) $40 \mathrm{~m}$.

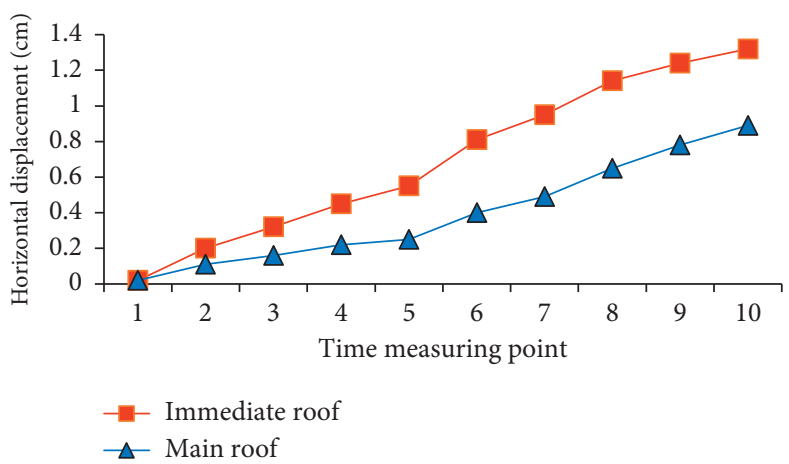

Figure 20: Horizontal displacement of roof strata. 


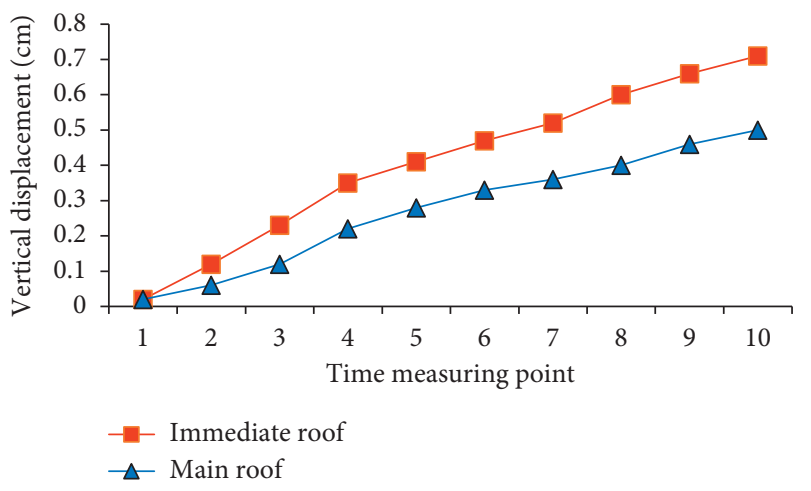

Figure 21: Vertical displacement of roof strata.

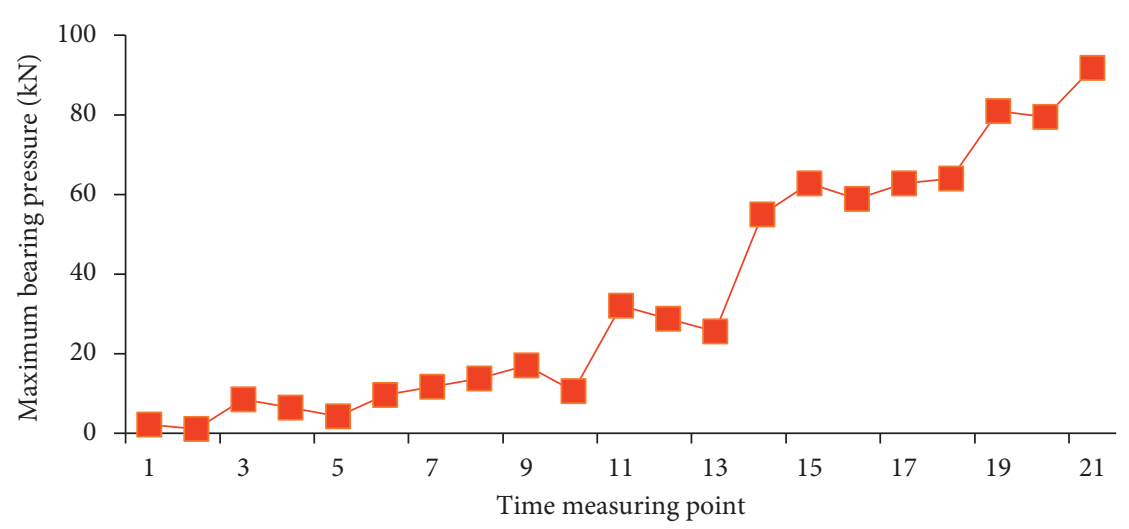

Figure 22: Stress curve of the 5th measuring point on the immediate floor.

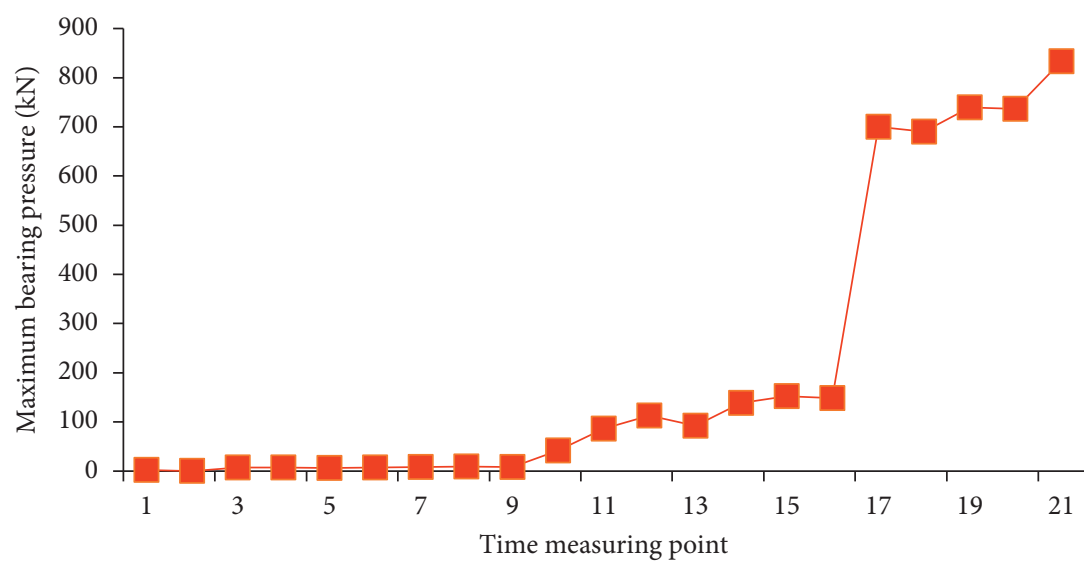

FIgURE 23: Stress curve of the 14th measuring point on the immediate roof.

length is $29 \mathrm{~m}$, and the compression of the filling body is $44 \mathrm{~mm}$. When the stope height reaches $40 \mathrm{~m}$ and is close to the bottom of the model, the roof has not collapsed, the height of the fracture zone reaches $16 \mathrm{~m}$, and the compression of the filling body is finally maintained at $47 \mathrm{~mm}$. The final shape of the surrounding rock deformation is shown in Figure 19(f).

After sorting out, the horizontal and vertical displacement data of the immediate roof and main roof are obtained, as shown in Figures 20 and 21.
It can be seen from Figures 20 and 21 that the movement of the overlying strata is regular, and the horizontal displacement of the roof to floor occurs; when the roof and floor are gradually compacted, the value of the displacement reaches the peak; the vertical displacement of the overlying strata has been continuously increasing; the vertical displacement is different depending on the strata level: the lower the strata level, the greater the vertical displacement. It can be seen that the roof and floor rocks still deform and move by adopting the backfill mining method, but the amount of deformation is small. 


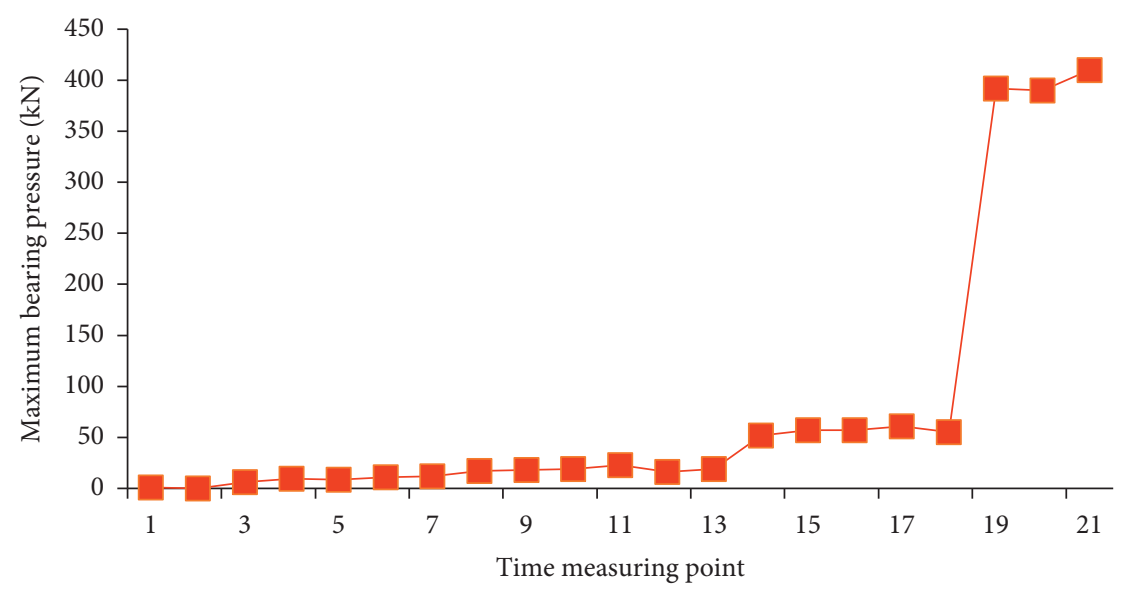

FiguRE 24: Stress curve of the 22nd measuring point on the main roof.

5.2.2. Analysis of the Stress Field. According to the simulation results, the maximum abutment pressure of the immediate floor appears at the 5th measuring point, with the maximum pressure being $91.8 \mathrm{kN}$. The maximum abutment pressure of the immediate roof appears at the 14th measuring point, with the maximum pressure being $833.1 \mathrm{kN}$. The maximum abutment pressure of the main roof appears at the 22nd measuring point, with the maximum pressure being $410.2 \mathrm{kN}$. The variation curves of the maximum abutment pressure of the roof and floor at each advancing stage of the working face are shown in Figures 22-24.

From the above analysis, it can be seen that the abutment pressure does not change significantly at the beginning. With the coal mining and filling at the working face, the immediate roof and the main roof are separated from the layer, the overlying strata is gradually compacted, and the abutment pressure shows a rising trend. When the separation of the main roof has the characteristics of stages, the pressure peak measured by the stress sheet is higher, but there is no periodic change, and the overall mining pressure is not obvious.

\section{Conclusion}

(1) The deflection equation of the inclined roof beam of the SDCS backfilling face is deduced, and the relevant parameters of the test mine are substituted into the equation. It is concluded that the maximum deflection is located at $0.58 \mathrm{~L}$ of the working face, which indicates that the position of the maximum deflection of inclined roof beam in the filling area moved $16.0 \mathrm{~m}$ to the upper part of the working face under the support of gangue filling body.

(2) By simulating the movement, deformation, and failure law of surrounding rock in the SDCS caving as well as the backfilling method, it can be seen that with the increase of the stope height, the movement, deformation, and failure of surrounding rock using the backfilling method grows slowly, and the increase of the strain is relatively stable with no sharp increases; the final horizontal deformation and subsidence values are controlled at $247 \mathrm{~mm}$ and
$353 \mathrm{~mm}$, respectively, which are $55.9 \%$ and $45 \%$ lower than those of caving, respectively; the range and degree of the surrounding rock disturbed by the mining stress are lower, and the stress concentration of the unmined pillar is greatly reduced.

(3) According to the physical similarity simulation experiment, the SDCS filling mining can slow down the movement speed and deformation of the overlying strata. The main failure forms of the roof strata are bending, separation, and fracture, and the deformation of roof surrounding rock is much greater than that of the floor. The abutment pressure of roof strata does not change greatly at the beginning, but with the separation of immediate roof and main roof, the overlying strata gradually compact, the abutment pressure increases, with the maximum abutment pressure appearing in the immediate roof, and the mine pressure behavior is not obvious.

(4) The results of numerical simulations, physical similarity simulation experiment, and model calculations are in good agreement, and the models are robust, which can provide theoretical bases for the studies on the movement law of the overlying strata in SDCS.

\section{Data Availability}

The data used to support the findings of this study are available from the corresponding author upon request.

\section{Conflicts of Interest}

The authors declare that there are no conflicts of interest regarding the publication of this paper.

\section{Authors' Contributions}

Wenyu Lv developed the idea and edited the paper. Kai Guo designed and analyzed of mathematical model. Jianhao Yu carried out the simulation work. Xufeng Du carried out the physical similarity simulation experiment. Kun Feng carried out the data collection. 


\section{Acknowledgments}

The authors thank the Sichuan Coal Industry Group Co., Ltd. for data collection. This study was financially supported by the National Natural Science Foundation of China (nos. 51974226 and 51634007), the Research Fund of Henan Key Laboratory for Green and Efficient Mining and Comprehensive Utilization of Mineral Resources (Henan Polytechnic University) (no. KCF202001), the Research Fund of Shaanxi Key Laboratory of Coal Mine Water Disaster Prevention and Control Technology (no. 2020SKMS02) and the Major Science and Technology Innovation Projects in Shandong Province (no. 2019JZZY020326).

\section{References}

[1] Y. P. Wu, D. F. Yun, P. S. Xie et al., "Progress practice and scientific issues in steeply dipping coal seams fully-mechanized mining," Journal of China Coal Society, vol. 45, no. 1, pp. 24-34, 2020.

[2] J. C. Wang, W. J. Wei, J. W. Zhang et al., "Stability analysis of support around the longwall top-coal caving mining in steeply thick coal seam," Journal of China Coal Society, vol. 42, no. 11, pp. 2783-2791, 2017.

[3] J. He, L. M. Dou, J. R. Cao et al., "Mechanism of rock burst in steep and extremely thick coal seam using horizontal section top-coal caving," Journal of China Coal Society, vol. 45, no. 5, pp. 1701-1709, 2020.

[4] G. Han, Q. J. Qi, and T. J. Cui, "Mining plan simulation and rock migration analysis in steep seam mining," Journal of Mining \& Safety Engineering, vol. 33, no. 4, pp. 618-623+629, 2016.

[5] Y. Yuan, S. Tu, F. Wang, X. Zhang, and B. Li, "Hydraulic support instability mechanism and its control in a fullymechanized steep coal seam working face with large mining height," Journal of the Southern African Institute of Mining and Metallurgy, vol. 115, no. 5, pp. 441-447, 2015.

[6] Y. P. Wu, "Controlling pattern for dynamic stability of system "roof-support-floor"” Journal of China Coal Society, vol. 32, no. 4, pp. 341-346, 2007.

[7] Y. P. Wu, K. Z. Liu, and D. F. Yun, "Research progress on the safe and efficient mining technology of steeply dipping seam," Journal of China Coal Society, vol. 39, no. 8, pp. 1611-1618, 2014.

[8] H. S. Tu, S. H. Tu, F. Chen et al., "Study on the deformation and fracture feature of steep inclined coal seam roof based on the theory of thin plates," Journal of Mining \& Safety Engineering, vol. 31, no. 1, pp. 49-54+59, 2014.

[9] Y. M. Li, Research on Stability of Overlying Strata and Reasonable Waterproof Coal Pillar with Backfilling in Steep Seam under Water Body, China University of Mining and Technology, Xuzhou, China, 2012.

[10] M. B. Zhai, Y. M. Li, and Z. C. Sun, "Floor stress distribution and strata movement control of backfilled mining in steep inclined seam," Coal Engineering, vol. 44, no. 12, pp. 81-84, 2012.

[11] S. Y. Dong, Research on Mining with Gangue Backfill Steeply Inclined Coal Seam Group under Buildings, China University of Mining and Technology (Beijing), Beijing, China, 2017.

[12] Q. Yao, T. Feng, and Z. Liao, "Damage characteristics and movement of inclined strata with sublevel filling along the strike in the steep seam," Journal of China Coal Society, vol. 42, no. 12, pp. 3096-3105, 2017.

[13] P. S. Xie, Response of Overburden Structure and its Stability Around the Longwall Mining Face Area in Steeply Dipping
Seam, Xi'an University of Science and Technology, Xi'an, China, 2011.

[14] S. C. Wang, L. M. Dou, Z. L. Mu et al., "Study on roof breakage-induced roadway coal burst in an extrathick steeply inclined coal seam," Shock and Vibration, vol. 2019, Article ID 2969483, 14 pages, 2019.

[15] F. H. Ma, L. Sun, and D. Li, "Numerical simulation analysis of covering rock strata as mining steep-inclined coal seam under fault movement," Transactions of Nonferrous Metals Society of China, vol. 21, no. s3, pp. 556-561, 2011.

[16] J. A. Wang and J. L. Jiao, "Criteria of support stability in mining of steeply inclined thick coal seam," International Journal of Rock Mechanics \& Mining Sciences, vol. 2016, no. 82, pp. 22-35, 2016.

[17] P. Gong, Z. G. Ma, R. R. Zhang et al., "Surrounding rock deformation mechanism and control technology for gob-side entry retaining with fully mechanized gangue backfilling mining: a case study," Shock and Vibration, vol. 2017, Article ID 6085941, 15 pages, 2017.

[18] P. Huang, A. J. S. Spearing, J. Feng et al., "Effects of solid backfilling on overburden strata movement in shallow depth longwall coal mines in West China," Journal of Geophysics \& Engineering, vol. 15, no. 5, pp. 2194-2208, 2018.

[19] X. J. Deng, J. X. Zhang, N. Zhou et al., "Upward slicing longwall-roadway cemented backfilling technology for mining an extra-thick coal seam located aquifers: a case study," Environmental Earth Sciences, vol. 76, no. 23, Article ID 789, 2017.

[20] Y. C. Yin, J. C. Zou, Y. B. Zhang et al., "Experimental study of the movement of backfilling gangues for goaf in steeply inclined coal seams," Arabian Journal of Geosciences, vol. 11, no. 12, Article ID 318, 2018.

[21] J. M. Li, Y. L. Huang, W. Y. Qi et al., "Loose gangues backfill body's acoustic emissions rules during compaction test: based on solid backfill mining," Computer Modeling in Engineering \& Sciences, vol. 115, no. 1, pp. 85-103, 2018.

[22] Y. C. Yin, T. B. Zhao, Y. B. Zhang et al., "An innovative method for placement of gangue backfilling material in steep underground coal mines," Minerals, vol. 9, no. 2, Article ID 107, 2019.

[23] H. W. Zhang, W. J. Zhang, and X. H. Wang, "Roof moving regulation of steeply pitching thick coal seam and mechanics analysis of flexible type shield," Journal of Liaoning Technical University, vol. 24, no. 1, pp. 57-59, 2005.

[24] C. Li, J. Xie, Z. Q. He et al., "Case study of the mining-induced stress and fracture network evolution in longwall top coal caving," Geomechanics and Engineering, vol. 22, no. 2, pp. 133-142, 2020.

[25] F. Wang, Q. Ma, C. Zhang, and G. Feng, "Overlying strata movement and stress evolution laws triggered by fault structures in backfilling longwall face with deep depth," Geomatics, Natural Hazards and Risk, vol. 11, no. 1, pp. 949-966, 2020. 